\title{
Biocatalytic Formation of Novel Polyesters with para-Hydroxyphenyl groups in the Backbone - Engineering Cupriavidus necator for production of high-performance materials from $\mathrm{CO}_{2}$ and electricity
}

\author{
Nils JH Averesch ${ }^{1,3 *}$, Vince E Pane ${ }^{2,3}$, Frauke Kracke ${ }^{1}$, Marika Ziesack ${ }^{4,5}$, Shannon N Nangle ${ }^{4,5}$, Pamela A \\ Silver ${ }^{4,6}$, Robert W Waymouth ${ }^{2,3}$, Craig S Criddle ${ }^{1,3}$ \\ (1) Department of Civil and Environmental Engineering, Stanford University, CA, USA \\ (1) Department of Chemistry, Stanford University, CA, USA \\ (3) Center for the Utilization of Biological Engineering in Space, CA, USA
}

(4) Wyss Institute for Biologically Inspired Engineering, MA, USA

(5) Circe BioScience, MA, USA

(6) Harvard Medical School, MA, USA

*Correspondence: nils.averesch@uq.net.au

\begin{abstract}
Synthetic materials are integral components of consumables and durable goods and indispensable in our modern world. Polyesters are the most versatile bulk- and specialty-polymers, but their production is not sustainable, and their fate at end-of-life of great concern. Bioplastics are highly regarded alternatives but have shortcomings in material properties and commercial competitiveness with conventional synthetic plastics. These constraints have limited the success in global markets. Enabling bio-production of advanced bioplastics with superior properties from waste-derived feedstocks could change this.

We have created microbial cell factories that can produce a range of aliphatic and aromatic polyesters. A $\Delta$ phaC1 mutant of Cupriavidus necator $\mathrm{H} 16$ was complemented with hydroxyacyl-CoA transferases from either Clostridium propionicum (pct540) or Clostridium difficile (hadA), respectively. These were combined with a mutant PHA synthase (phac1437) from Pseudomonas sp. MBEL 6-19, which rescued the PHA phenotype of the knock-out mutant and allowed polymerization of various hydroxy carboxylates, including phloretic acid. This is the first-time, incorporation of an aromatic ring in the backbone of a biological polyester was achieved. Polymers contain para-hydroxyphenyl subunits are structurally analogous to synthetic aromatic polyesters like PET and high-strength polyarylates.

In a further advance, the transgenic strain was cultivated in a bio-electrochemical system under autotrophic conditions, enabling synthesis of aromatic bio-polyesters from $\mathrm{H}_{2}$ and $\mathrm{O}_{2}$ generated in situ, while assimilating $\mathrm{CO}_{2}$. Follow-up elementary flux-mode analysis established the feasibility of de novo production of twenty different polyesters from five different carbon- and energy-sources. This comprehensive study opens the door to sustainable bio-production of high-performance thermoplastics and thermosets.
\end{abstract}




\title{
Significance statement
}

New biomaterials can facilitate transition to a carbon-neutral chemical industry and a circular economy while at the same time preventing accumulation of plastic wastes in the environment. This can be accomplished by developing "drop-in" replacements for existing fossil carbon-based plastics. To that end, this work demonstrates for the first time that biocatalytic polymerization can incorporate an aromatic para-hydroxyphenyl carbonic acid into the backbone of a bio-polyester. This was accomplished using a genetically engineered microbial cell factory that assimilates carbon dioxide using hydrogen that is produced electrochemically in situ. A bio-electrochemical system eliminates the need for external supply of oxyhydrogen and avoids explosive mixtures, opening the door for sustainable production of biomaterials analogous to aromatic bulk-polyesters such as PET and high-performance "liquid-crystal polymers".

\section{Highlights}

- $\quad$ Biocatalytic formation of aromatic polyesters with structural analogy to polyarylates

- $\quad$ Production of novel PHAs from $\mathrm{CO}_{2}$ and $\mathrm{H}_{2}+\mathrm{O}_{2}$ produced in situ in a bio-electrochemical system

- $\quad$ Expression-level of PHA synthase and molecular weight of polyesters are inversely correlated

- $\quad$ In silico design and analysis of pathways towards novel PHAs from different carbon-sources

\section{Keywords}

Polyhydroxyalkanoates, aromatic polyesters, bioplastics, C-1 feedstocks, microbial electrosynthesis

\begin{abstract}
Abbreviations
3HP, 3-hydroxypropionic acid; 4HB, 4-hydroxybutyric acid; 6HC, 6-hydroxycaproic acid; BES, bioelectrochemical system; BM, biomass; CDW, cell dry weight; DAP diaminopimelate; DSC, differential scanning calorimetry; EMA, elementary flux-mode analysis; GC-MS, gas chromatography-mass spectrometry; GPC, gel permeation chromatography; $\mathrm{HA}$, hydroxy acid; MA, mandelic acid; MES, microbial electrosynthesis; $M_{n}$, number-average molecular weight; $M S M$, mineral salts medium; $M_{w}$, weightaverage molecular weight; NMR, nuclear magnetic resonance; OD, optical density; PA, phloretic acid; PDI, polydispersity index; PET, polyethylene terephthalate; PHA, polyhydroxyalkanoate; PHB, polyhydroxybutyrate; PHBV, polyhydroxybutyrate-co-hydroxyvalerate; PheLA, phenyllactic acid; PLA, polylactic acid; RB, rich broth; rpm, rounds per minute; VFA, volatile fatty acid;
\end{abstract}




\section{Introduction}

\section{Background}

Modern society is based upon ever-increasing consumption of energy and material resources. The outcome is ever-increasing emissions of waste and pollutants $(1,2)$. Greenhouse gases have reached critical levels, and pollution fabrication of recalcitrant synthetic materials is ubiquitous and undeniable. A lifestyle and an economy dependent upon plastic consumption risks serious harm to the biosphere (3). To ensure a viable planet for generations to come, methods are needed to reduce waste accumulation while embracing readily available and renewable feedstocks (4). While plastic recycling is necessary for a circular economy, recycling alone will not prevent unintended release of synthetic materials into the environment. This is especially the case in single-use applications where the stability of plastics is as unnecessary as it is problematic (5). Bio-degradable materials derived from renewable feedstocks or from upcycling of existing materials are desirable (6) but materials derived from cultivated feedstocks are not necessarily climate friendly (7). Utilization of low-cost (waste) carbon-sources, such as C1-feedstocks for production of materials can potentially directly mitigate greenhouse gas emissions while avoiding competition with the food-industry (8). Such a strategy improves commercial competitiveness by decreasing feedstock cost (9). Especially useful are compounds that can substitute for or directly replace industrial (petrochemistrybased) polymers. Such bio-replacements are attractive because they do not require extensive modifications to the existing infrastructure for processing and manufacturing (minimal CapEx).

Polyhydroxybutyrate (PHB), a biological thermoplastic polyester, can be produced outgoing from nonedible, waste-derived carbon-sources, such as carbon dioxide or methane and could be a bio-degradable replacement for synthetic materials (10). Shortcomings in its material properties (11) and high production cost (9) have, however, hampered its adoption. This has been addressed, in part, by addition of comonomers that can tune material properties and generate a multitude of polyhydroxyalkanoates (PHAs) (11). The most prominent one, PHBV, is based on valeric acid, which is easily incorporated and benefits material properties, however, as an odd-number carbonic acid not readily bio-available. Alternatives exist, in particular, linear, short-chain PHAs have properties like high strength and flexibility that make them attractive and viable for specialty applications (12-14). PHAs with aromatic groups (in the side chain) have a wide range of properties, which are, however, hard to predict as they do not scale linearly with the fraction of aromatic co-monomer (15). In general, they are more amorphic than the highly crystalline PHB and therefore have increased glass-transition and higher degradation temperatures, allowing for a wider processing window. Specifically, poly(mandelite) (16) and poly(phenyllactide) (17), polymers of mandelic and phenyllactic acid, respectively, have been chemically synthesized and characterized, and these materials exhibit properties mimicking those of polystyrene. Recently, biological production of aromatic hydroxy acids from sugar and their incorporation into PHB co-polymers has been demonstrated through metabolic engineering of Escherichia coli (18). 
To date, all biocatalytically produced aromatic PHAs have contained the aromatic ring on a side chain (15). Incorporation of the aromatic ring into the backbone of the bio-polyester would conceivably result in vastly altered properties, yielding structural analogs to e.g., polyethylene terephthalate (PET) and polyarylates. Analog polyesters have been chemically synthesized and characterized based on natural hydroxy acids, e.g. glycolic and para-hydroxybenzoic acid (19), as well as 3-(para-hydroxyphenyl)propionic (phloretic) and 3-(para-hydroxyphenyl)acrylic acid (coumaric) acid (20). These "polyhydroxyarylates" exhibited liquid-crystal polymer properties and are potentially biodegradable.

\section{Concept}

This work explored microbial production of a wide range of thermoplastic materials from sustainable feedstocks in -vivo and in -silico. The chemolithoautotrophic 'knallgas' bacterium Cupriavidus necator was selected as chassis organism, as it is an excellent producer of bio-polyesters and can utilize various carbonand energy-sources, including carbon dioxide and oxyhydrogen (21). This well-characterized mixotroph grows rapidly to high cell densities and has previously been engineered for production of non-natural PHAs, including fatty acid-derived medium chain-length poly(3-hydroxyalkanoate)s and lactic acid copolymers, outgoing from $\mathrm{CO}_{2}$ and sustainable carbon-sources $(22,23)$, as well as aromatic PHAs from externally supplied precursors (24). Expanding upon these previous studies, a $\triangle p h a C 1$ knock-out mutant of $C$. necator $\mathrm{H} 16$ was complemented with the genes for a hydroxyacyl-CoA transferase (pct540 or hadA from Clostridium propionicum or Clostridium difficile, respectively) and evolved PHA synthase (phaC1437 from Pseudomonas sp. MBEL 6-19) ), which had previously been employed for production of aromatic PHAs in a different context $(18,25)$. This allowed biosynthesis and subsequent characterization of several straight chain aliphatic and aromatic PHAs by complementing and repurposing natural poly(3-hydroxbutyrate) (PHB) synthesis (cf. figure 1). 


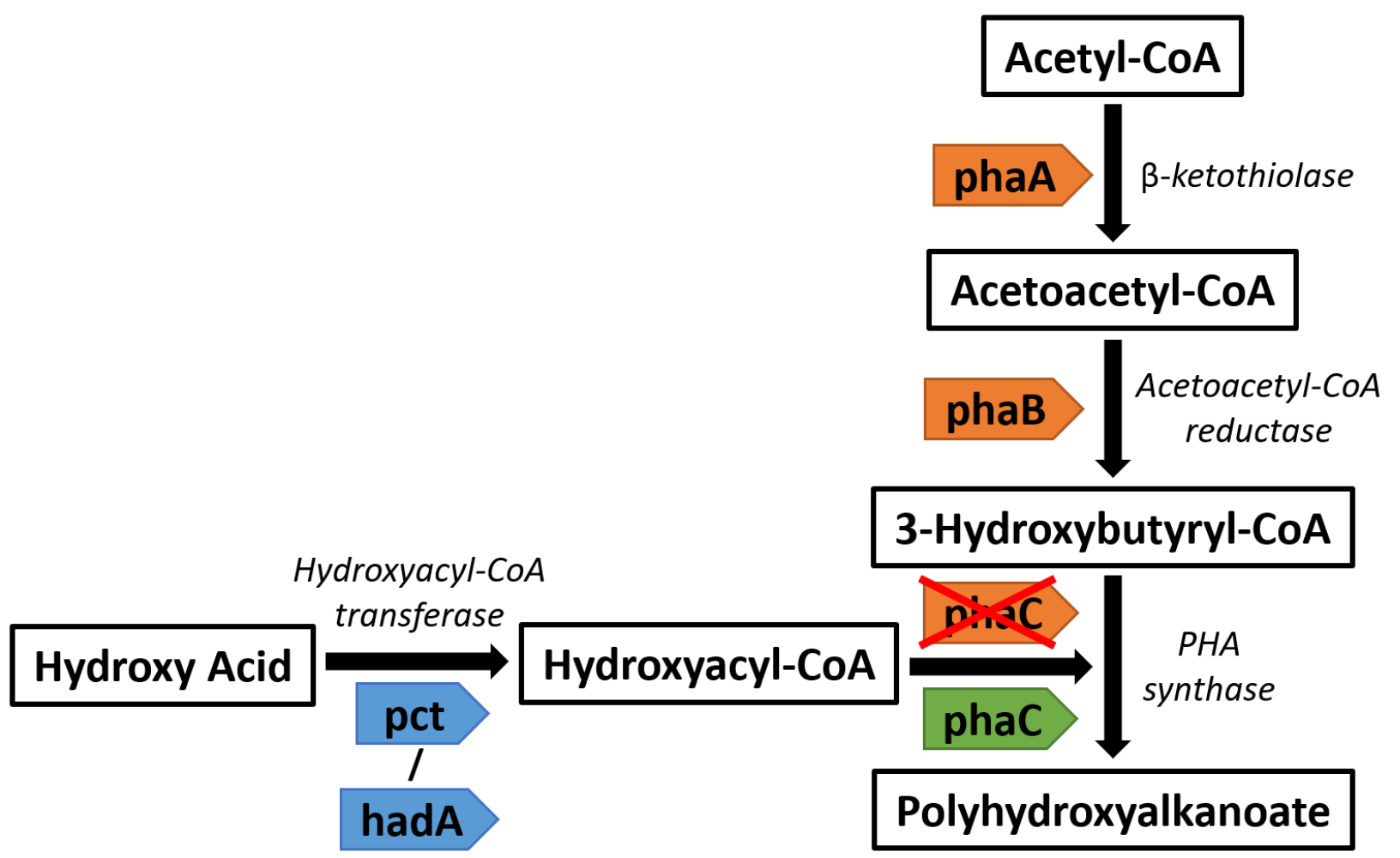

Figure 1: Partial breakdown of natural biochemical pathway for poly(3-hydroxybutyrate) synthesis (vertical) and synthetic biochemical pathway for formation of modified bio-polyesters (horizontal). Involved genes (in chevrons) are highlighted orange for natural, or blue (CoA transferase, pct / hadA) and green (PHA synthase, phaC), respectively, in case of heterologous (manually introduced) genes.

\section{Results and Discussion}

\section{Formation of Non-Natural Polyesters from Externally Supplemented Precursors}

Introduction of the heterologous PHA synthase into C. necator $\mathrm{H} 16 \triangle$ phaC1 could rescue the PHB-negative phenotype of the knock-out mutant. Per-biomass yield was comparable to the wild-type $\left(\approx 60 \% \mathrm{~W}_{\mathrm{PHA}} / \mathrm{W}_{\mathrm{BIOMASS}}\right.$, data not shown); remarkably, bio-polyesters were formed independent of induction $\left(\mathrm{P}_{\mathrm{BAD}}\right)$ of expression of the heterologous genes, merely by limiting the Nitrogen-source. Nuclear magnetic resonance $\left({ }^{1} \mathrm{H}-\mathrm{NMR}\right)$ spectroscopy revealed that the polymer was composed of 3-hydroxybutyrate with small fractions of other hydroxy acids, likely derivatives of higher fatty acids.

Several rounds of feeding experiments with various hydroxy carbonates were conducted in batch (shakeflask) cultures. The composition of the obtained polyester, as well as the respective fraction of non-natural monomers in the co-polymer were determined by means of gas-chromatography coupled mass-spectroscopy (GC-MS), as well as ${ }^{1} \mathrm{H}$-NMR spectroscopy, which was in certain cases complemented with ${ }^{13} \mathrm{C}-\mathrm{NMR}$ spectroscopy. The different polyesters that were formed from the hydroxy acids supplemented in the growth medium, and the ratios of the different repeat units are given in table 1. 
Table 1: Polymers obtained from feeding experiments of $C$. necator $\mathrm{H} 16$ (wild-type and engineered strains) with precursors and fraction of non-natural monomer in the obtained co-polyester. Ratios are based on ${ }^{1} \mathrm{H}-\mathrm{NMR}$ spectroscopy, those obtained from GC-MS can be found in supplementary material 1.

\begin{tabular}{|c|c|c|c|c|}
\hline \multicolumn{2}{|c|}{ Precursor / Concentration } & \multicolumn{3}{|c|}{ Strain / co-polymer \& ratio of repeat units } \\
\hline & & $\begin{array}{l}\text { H16 (wild- } \\
\text { type) }\end{array}$ & $\begin{array}{l}\text { H16 } \Delta \text { phaC1 } \Delta \text { phaC1 } \\
\text { pct540 phaC1437 }\end{array}$ & $\begin{array}{c}\mathrm{H} 16 \Delta \text { phaC1 hadA } \\
\text { phaC1437 }\end{array}$ \\
\hline- & N/A & P3HB & $P 3 \mathrm{HB}$ & P3HB \\
\hline glycolic acid & $20 \mathrm{mM}$ & P3HB & P3HB & P3HB \\
\hline D-lactic acid & $20 \mathrm{mM}$ & P3HB & P3HB & P3HB \\
\hline 3-hydroxypropionic acid & $20 \mathrm{mM}$ & P3HB & $\begin{array}{l}P(3 \mathrm{HB}-c o-3 \mathrm{HP}) \\
\quad \approx 100: 12^{\$}\end{array}$ & $\begin{array}{l}P(3 \mathrm{HB}-\mathrm{CO}-3 \mathrm{HP}) \\
\quad \approx 100: 1^{\$}\end{array}$ \\
\hline 4-hydroxybutyric acid & $20 \mathrm{mM}$ & $\begin{array}{l}P(3 \mathrm{HB}-c 0-4 \mathrm{HB}) \\
\quad \approx 100: 9\end{array}$ & $P(3 \mathrm{HB}-c o-4 \mathrm{HB}) \approx 1: 1$ & $\begin{array}{l}P(3 \mathrm{HB}-c o-4 \mathrm{HB}) \\
\approx 10: 1\end{array}$ \\
\hline 6-hydroxycaproic acid & $<10 \mathrm{mM}^{*}$ & $\begin{array}{l}P(3 \mathrm{HB}-c o-4 \mathrm{HB}) \\
\quad \approx 100: 13\end{array}$ & $\begin{array}{l}P(3 \mathrm{HB}-c o-4 \mathrm{HB}) \\
\quad \approx 100: 13: 8\end{array}$ & $\begin{array}{c}P(3 \mathrm{HB}-c o-4 \mathrm{HB}-c o- \\
\quad 6 \mathrm{HC}) \approx 100: 5: 2\end{array}$ \\
\hline $\begin{array}{c}\text { 2-hydroxy- } \\
\text { 4-phenylbutyric acid }\end{array}$ & $10 \mathrm{mM}$ & n.d. & P3HB & $\begin{array}{c}P(3 \mathrm{HB}-\mathrm{co}-2 \mathrm{H} 4 \mathrm{PheB}) \\
\approx 20: 1\end{array}$ \\
\hline D-phenyllactic acid & $10 \mathrm{mM}$ & n.d. & P3HB & $\begin{array}{c}P(3 \mathrm{HB}-\text { co-PheLA }) \\
\approx 2: 1\end{array}$ \\
\hline mandelic acid & $5 \mathrm{mM}$ & n.d. & P3HB & $P(3 \mathrm{HB}-\mathrm{Co}-\mathrm{MA}) \approx 4: 1$ \\
\hline phloretic acid & $5 \mathrm{mM}$ & n.d. & P3HB & $\begin{array}{l}P(3 \mathrm{HB}-\mathrm{co}-\mathrm{PA}) \\
\quad \approx 100: 1\end{array}$ \\
\hline
\end{tabular}

* approx. $10 \mathrm{mM}$ supplied, above solubility limit, \$ only NMR, unconfirmed by GC-MS. Abbreviations: n.d. $=$ not determined, $3 \mathrm{HP}=3$-hyroxypropionate, $3 \mathrm{HB}=3$-hydroxybutyrate, $4 \mathrm{HB}=4$-hydroxybutyrate, $6 \mathrm{HC}=6$-hydroxycaproate $\quad 2 \mathrm{H} 4 \mathrm{PheB}=2$-hydroxy-4-phenylbutyrate, $\quad$ PheLA = phenyllactate, $\mathrm{MA}=$ mandelate, $\mathrm{PA}=$ phloretate .

Throughout the batch cultivations, which were conducted on fructose as carbon- and energy-source (for experimental simplicity), some of the polymer-precursors exhibited toxicity, which dictated the maximum deployable concentrations, as per table 1 . In particular, the hydroxypropionic acids affected the growth rate negatively (data not shown). While not toxic, poor solubility of 6 -hydroxycaproic acid $(<10 \mathrm{mM})$ limited the final concentration of the $\omega$-fatty acid in the growth medium. The aromatic hydroxy acids also appeared to be rather toxic, esp. 2-hydroxy-4-phenylbutyric (2H4PheB) and mandelic acid (MA) could only be supplied at $10 \mathrm{mM}$ and $5 \mathrm{mM}$, respectively, if not to inhibit growth completely. 
No co-polymers containing glycolic and lactic acid were obtained. It is likely that these short organic acids were catabolized before they could be polymerized, as these volatile fatty acids (VFAs) are known to be good substrates for $C$. necator (26-28). The presence of co-polymers with 3-hydroxypropionic acid (3HP) is ambiguous: while ${ }^{1} \mathrm{H}-\mathrm{NMR}$ spectra were in good accordance with literature (29) (triplet resonance at $4.33 \mathrm{ppm}$ indicative of the C3-methylene), GC-MS could not confirm the presence of $P(3 \mathrm{HB}-\mathrm{Co}-3 \mathrm{HP})$. Incorporation-level of 4-hydroxybutyric acid $(4 \mathrm{HB})$ by the engineered strain that carried hadA and phaC1437 and by the wild-type was similar $(\approx 10 \%)$, indicating that (a) C. necator's native CoA transferase "YdiF" / pct accepts 4HB well enough (30) and (b) the natural PHA synthase (phaC1) is promiscuous enough to polymerize the non-natural hydroxy carbonic acid. Deducted therefrom it appears that the heterologous enzymes offer no significant advantage for formation of a 4-hydroxybutyrate co-polymer over the native ones. GC-MS, however, did not detect any non-natural PHAs in control experiments with the wild-type (cf. supplementary material 1, Table S2).

Importantly, the strain carrying pct540 and phaC1437 produced a co-polymer with a high fraction of $4 \mathrm{HB}$ (approx. 66\%, cf. figure 3A). NMR and GPC further indicated that the obtained polyester was a block-copolymer. The strain showed considerably reduced growth, as compared to the wild-type or the other transgenic mutant, but only when expression was induced. The retardation of growth correlated with the onset of expression; fructose consumption also came to a halt at that point (cf. supplementary material 1 , figures S1, S2 \& S3, S4). This indicates severe protein toxicity, which is a known problem of propionylCoA transferases (25). Altogether, it seems that overall metabolism stalled, which would also have halted 3-hydroxybutyrate $(3 \mathrm{HB})$ formation. The high $4 \mathrm{HB}$ content in the PHA produced by the pct540 strain is potentially a result of that effect, rather than the heterologous function(s) of the expressed enzyme(s). This hypothesis can also explain the block-co-polymer - while in the beginning (pre-induction) a polymer that is mostly constituted of intracellular $3 \mathrm{HB}$ would be (constitutively) produced, in the end (after induction) $3 \mathrm{HB}$ would deplete, allowing only pure catalysis to take place, solely adding externally provided $4 \mathrm{HB}$ to the polymer chain. This also explains the comparatively high PDI ( 3, cf. supplementary material 1 , Table S1) of the co-polymer, which is a result of the polymers heterogeneity (size differences between the different chains).

When supplying 6-hydroxycaproic acid $(6 \mathrm{HC})$, the engineered strains and the wild-type both formed nonnatural PHAs: while the wild-type produced a co-polymer containing $4 \mathrm{HB}$, the PHA derived from the engineered strain contained $4 \mathrm{HB}$ and $6 \mathrm{HC}$ (cf. figure $3 \mathrm{~B}$ ). In all cases presence of $4 \mathrm{HB}$ is attributed to the original $C 6 \omega$-fatty acid undergoing $\beta$-oxidation to a $C 4 \omega$-fatty acid. In the engineered strain the highly active heterologous PHA synthase, potentially in concert with the over-expressed CoA transferase, accelerates formation of the polymer, partially outcompeting $\beta$-oxidation. This was only observable from NMR spectroscopy, GC-MS analysis did not show any incorporation of 6HC into the PHA by the wild-type, nor $4 \mathrm{HB}$ in samples from cultures where $6 \mathrm{HC}$ was supplied as precursor. 
Aromatic hydroxy acids were incorporated into the polymer only by the strain carrying hadA and phaC1437. Significant aromatics content was obtained, and fractions differed depending on the precursor: while external supply of $2 \mathrm{H} 4 \mathrm{PheB}$ yielded a polymer with a fraction of the aromatic one order of magnitude lower than 3HB (cf. figure $3 \mathrm{C}$ ), incorporation of phenyllactic acid (PheLA) yielded a PHA that contained a high fraction (same order of magnitude as 3HB) of aromatic repeat unit (cf. figure 3D). This led to drastically changed polymer properties, including reduced melting point and increased solubility (e.g., readily soluble in acetone). The dry polymer appeared ductile at room temperature. The polymer obtained from MA (cf. figure $3 \mathrm{E}$ ) had about half the aromatics content of the PheLA co-polymer, which may be attributed to the lower (half) concentration of precursor that was supplied.

Most significantly, also the para-hydroxyphenyl compound 'phloretic acid' was successfully polymerized by the hadA-strain (cf. figure 3F). Albeit only a minor fraction of the aromatic compound was incorporated into the backbone of the bio-polyester, to our knowledge it is the first-time something like this has been accomplished, paving the way to a new class of bio-available materials: co-polymers with the aromatic ring in the backbone have structural analogy to polyarylates. In future, homopolymers or copolymerization of para-hydroxyphenyl or para-hydroxybenzoic acids with straight-chain aliphatic hydroxy acids could generate high-performance materials with structural analogy to e.g., PET or liquid crystal polymers like Vectran ${ }^{\mathrm{TM}}$. 
A

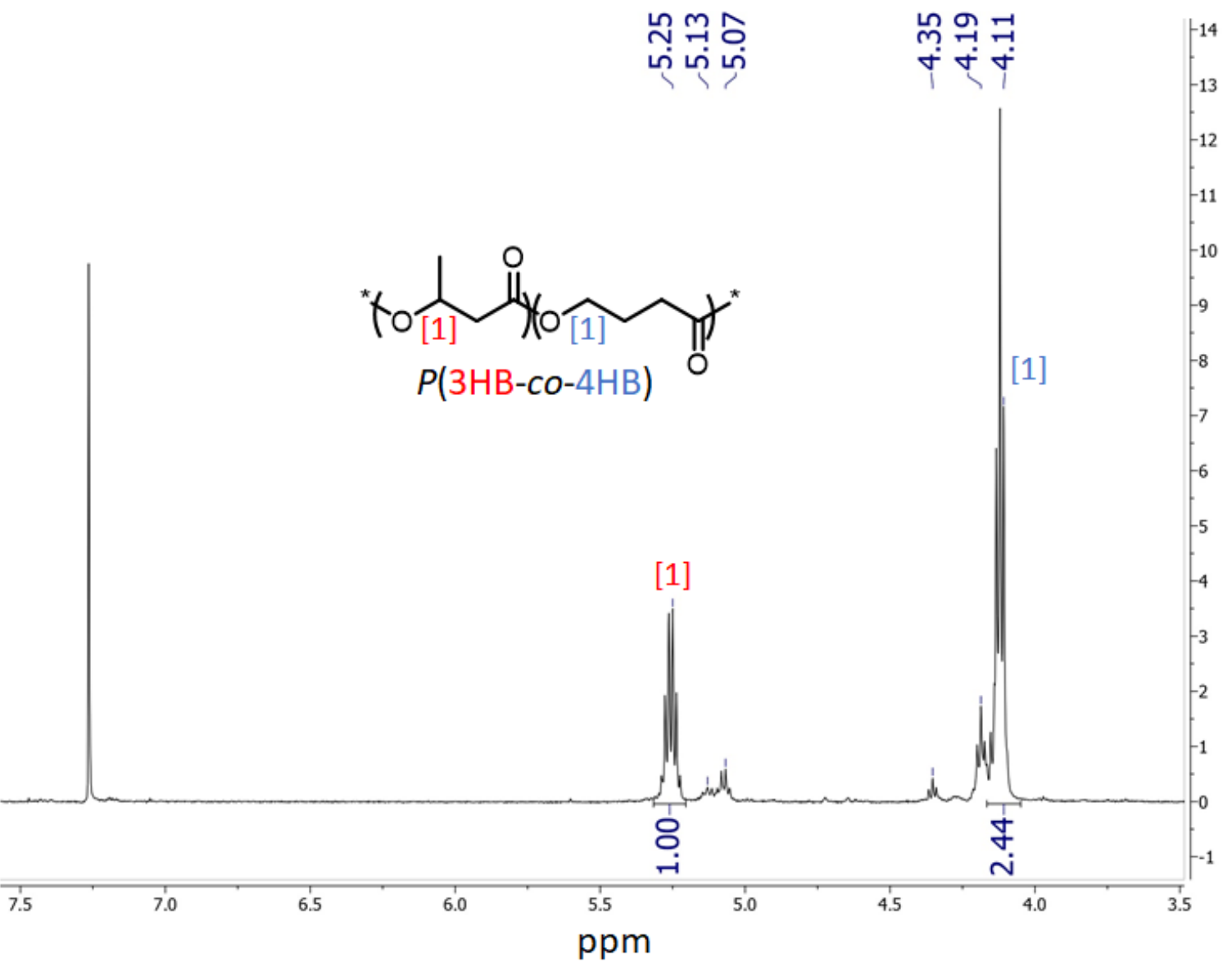

B

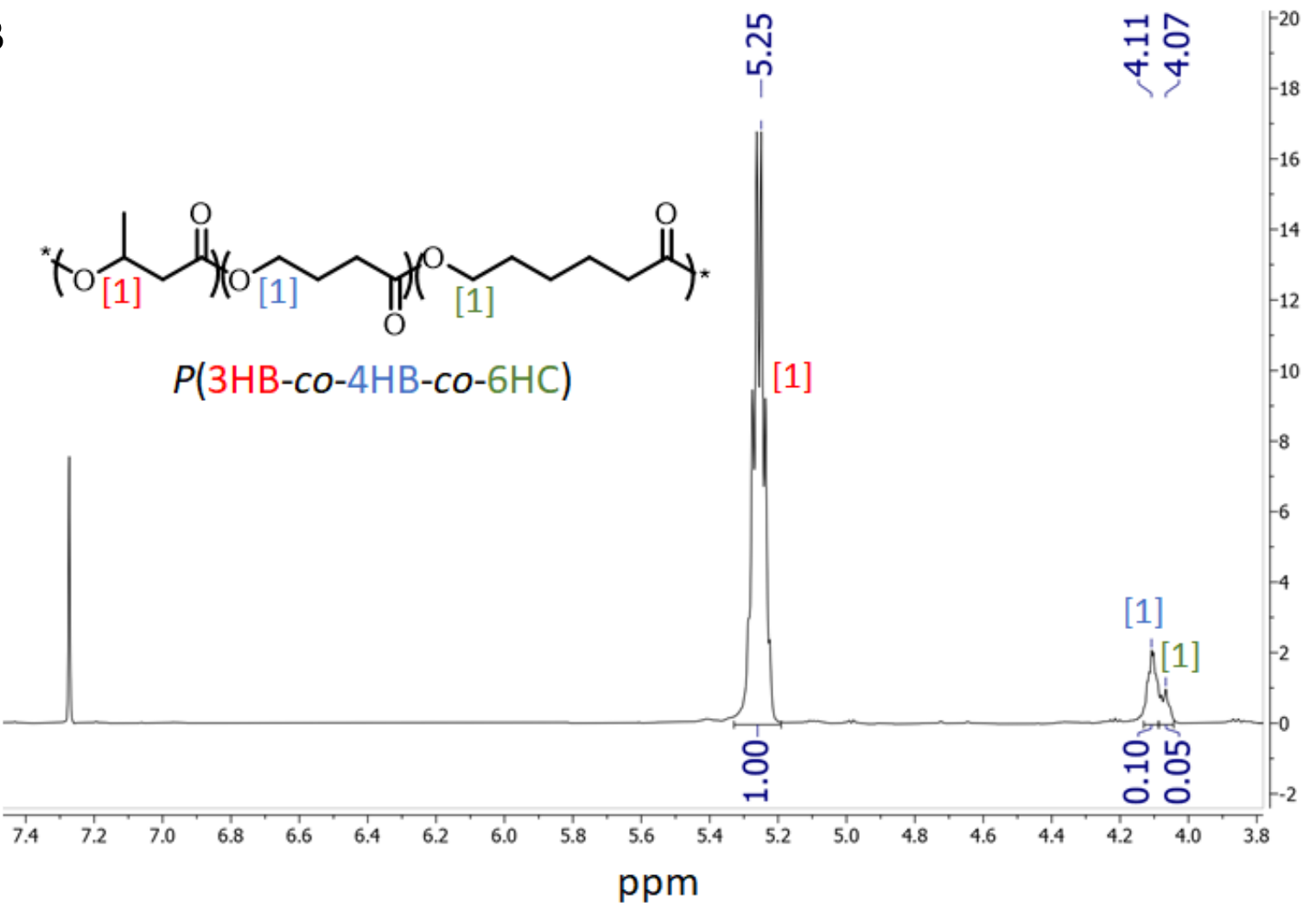



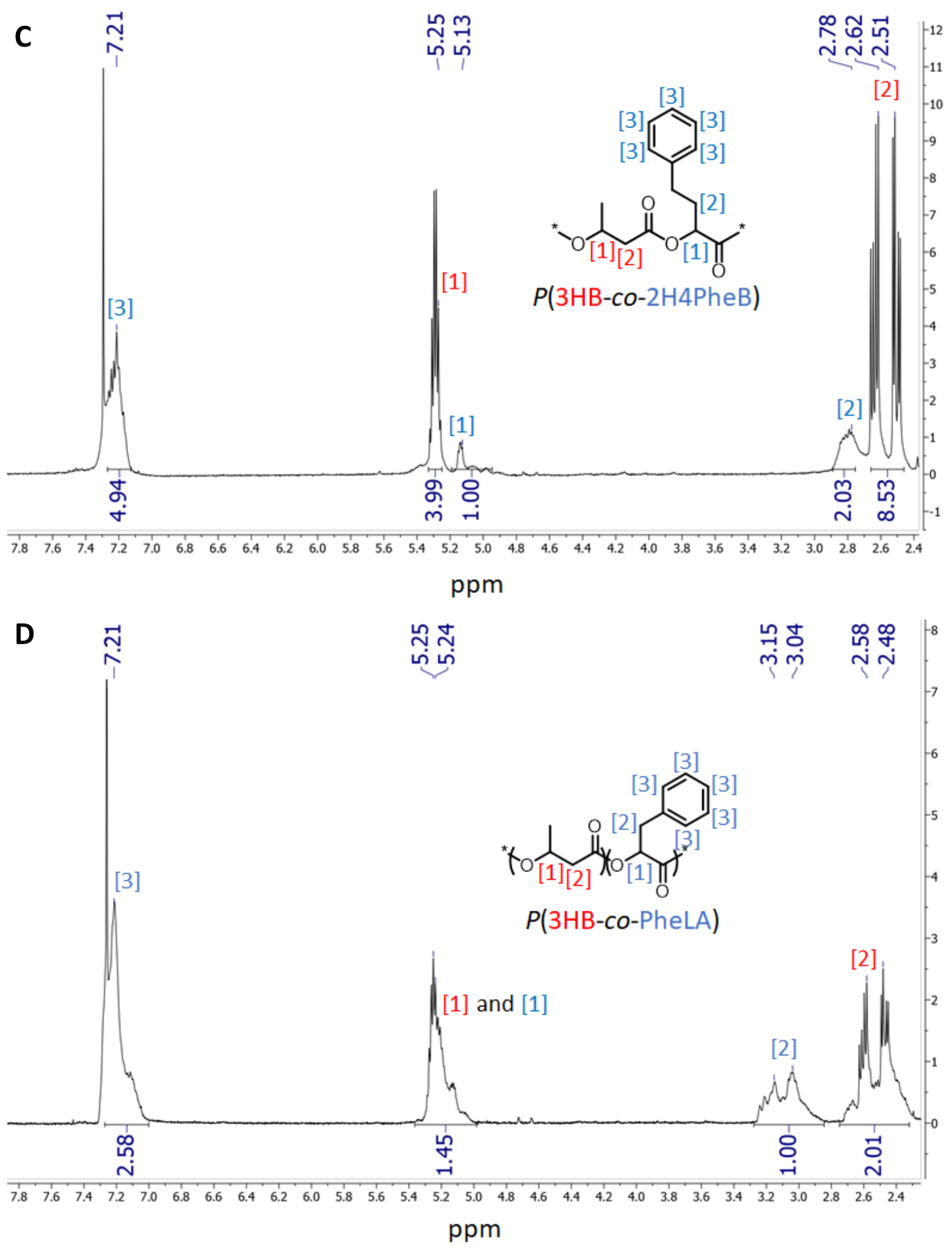


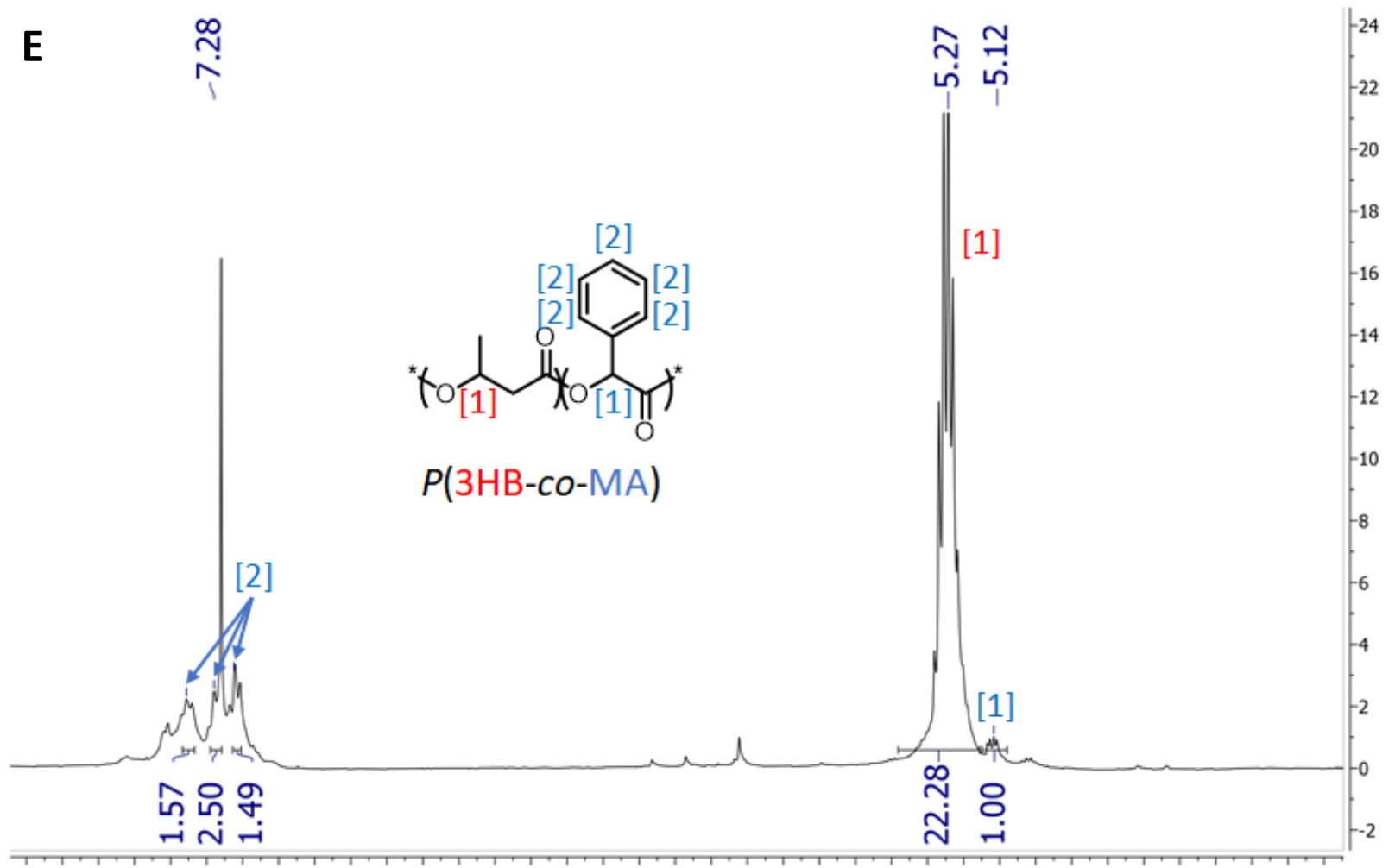

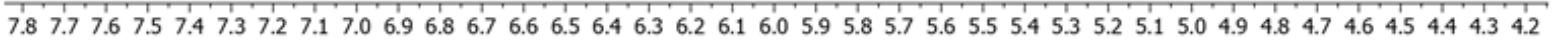

ppm

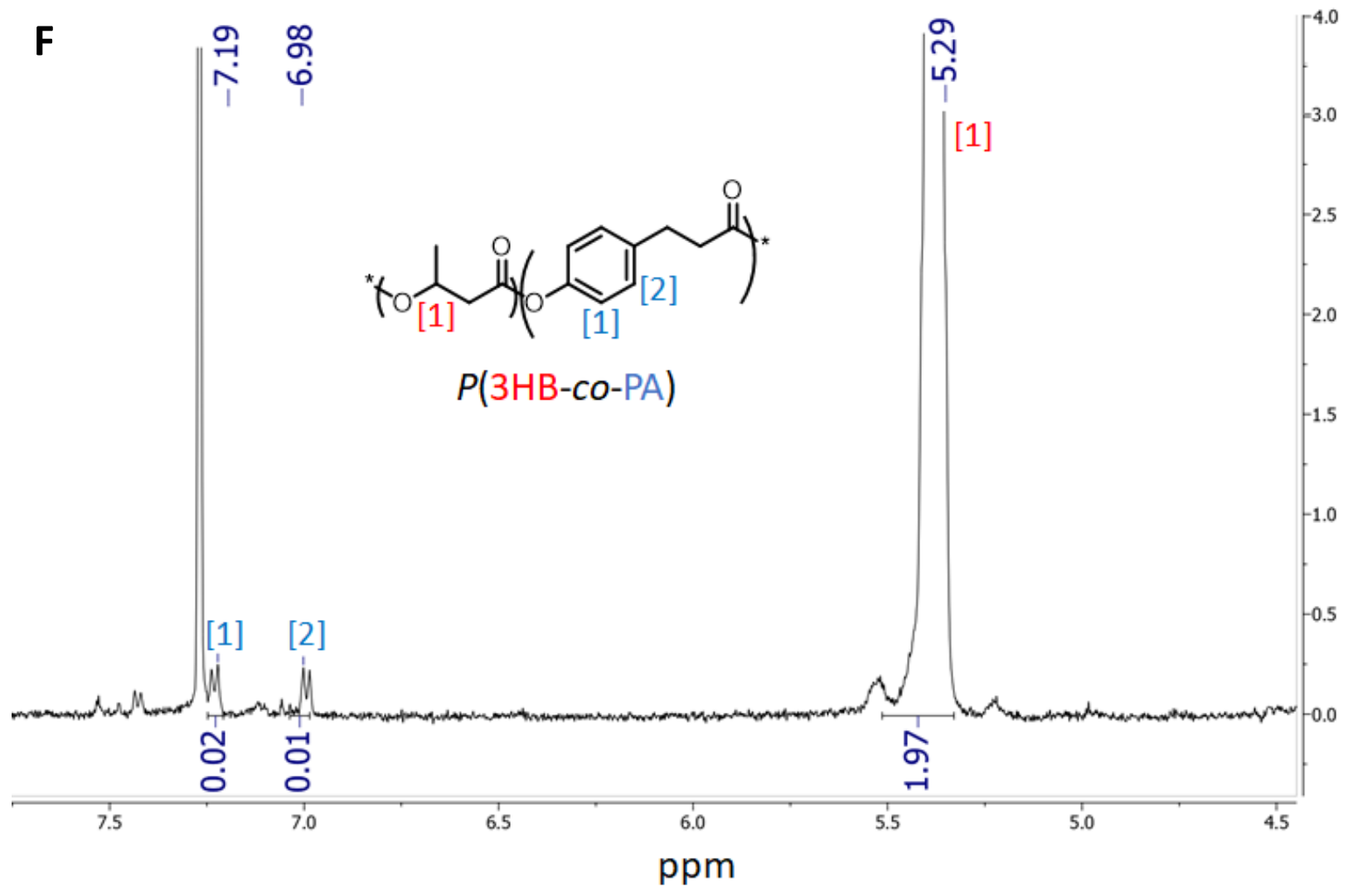


Figure 3: ${ }^{1} \mathrm{H}-\mathrm{NMR}$ spectra of $P(3 \mathrm{HB}-\mathrm{co}-4 \mathrm{HB})$ produced by $\mathrm{C}$. necator H16 $\Delta$ phaC1 pCM66T_PBAD-pct540-phaC1437 (A) as well as $P(3 \mathrm{HB}-c o-4 \mathrm{HB}-c o-6 \mathrm{HC})$ (B), $P(3 \mathrm{HB}-c o-2 \mathrm{H} 4 \mathrm{PheB}$ (C), $P$ (3HB-co-PheLA) (D), P(3HB-co-MA) (E), and $P(3 H B-c o-P A)(F)$ produced by $C$. necator H16 $\triangle$ phaC1 pCM66T_PBAD-hadA-phaC1437. Areas are indicative of the ratios for $3 \mathrm{HB}$ to non-natural repeat units. (A): In addition to the P3HB sextet resonance at $5.25 \mathrm{ppm}$, a triplet resonance at $4.11 \mathrm{ppm}$ shows that the $\mathrm{C} 4-$ methylene of the $4 \mathrm{HB}$ repeat is present, indicating incorporation of $4 \mathrm{HB}$ into the polymer. The large fraction of $\mathrm{P} 4 \mathrm{HB}$ causes multiple $\mathrm{P} 3 \mathrm{HB}$ peaks because of different possible orders in the polymer (e.g., -3HB-P3HB-P4HB-, -P4HB-P3HB-P4HB-, -P4HB-P3HB-P3HB-, -P3HB-P4HB-P3HB-). (B): In addition to the $\mathrm{P} 3 \mathrm{HB}$ sextet resonance at $5.25 \mathrm{ppm}$ and $\mathrm{P} 4 \mathrm{HB}$ triplet resonance at $4.11 \mathrm{ppm}$, a triplet resonance at 4.07 ppm shows that the $\mathrm{C6}$-methylene of the $6 \mathrm{HC}$ repeat is present, indicating incorporation of $6 \mathrm{HC}$ into the polymer. (C): In addition to the P3HB sextet resonance at $5.25 \mathrm{ppm}$, a triplet resonance at $5.13 \mathrm{ppm}$ shows that the C2methine of the $2 \mathrm{H} 4 \mathrm{PheB}$ repeat is present. The broad aromatic multiplet resonance at $7.21 \mathrm{ppm}$ is also indicative of P2H4PheB. (D): The P3HB sextet resonance at $5.25 \mathrm{ppm}$ overlaps with the methine PPheLA resonance, so the methylene doublet resonances of $3.15 \& 3.04 \mathrm{ppm}$ and $2.58 \& 2.48 \mathrm{ppm}$ were used to show the presence of P3HB and PPheLA respectively. The broad aromatic resonance at $7.21 \mathrm{ppm}$ is also indicative of PPheLA. (E): In addition to the P3HB sextet resonance at $5.25 \mathrm{ppm}$, a multiplet resonance at $5.12 \mathrm{ppm}$ shows that the $\mathrm{C} 2$-methine of the MA repeat is present. The broad aromatic multiplet resonance at $7.28 \mathrm{ppm}$ is also indicative of MA. (F): In addition to the P3HB sextet resonance at $5.25 \mathrm{ppm}$, two doublet resonances at 7.19 and $6.98 \mathrm{ppm}$ show that the aromatic PA repeat is present, indicating incorporation of the para-hydroxyphenyl unit into the polymer.

\section{Impact of Genetic Engineering on PHB Production and Composition}

We further characterized PHB production of the genetically engineered strains in comparison to the wildtype $C$. necator $\mathrm{H} 16$. The molecular weight of polymer produced by the transgenic strain was compared to the polymer derived from wild-type $C$. necator $\mathrm{H} 16$ by means of gel-permeation chromatography (GPC): bio-polyester derived from the engineered strain (not induced) was approx. 5-times lower $M_{W}$ (or $M_{n}$ ) than that produced by the wild-type (figure 2). Induction of the engineered strain (i.e., over-expression of the heterologous genes) resulted in another 5-fold reduction in molecular weight of the produced polymer. It thus appears that enzyme expression-level and polymer chain-length are inversely correlated.

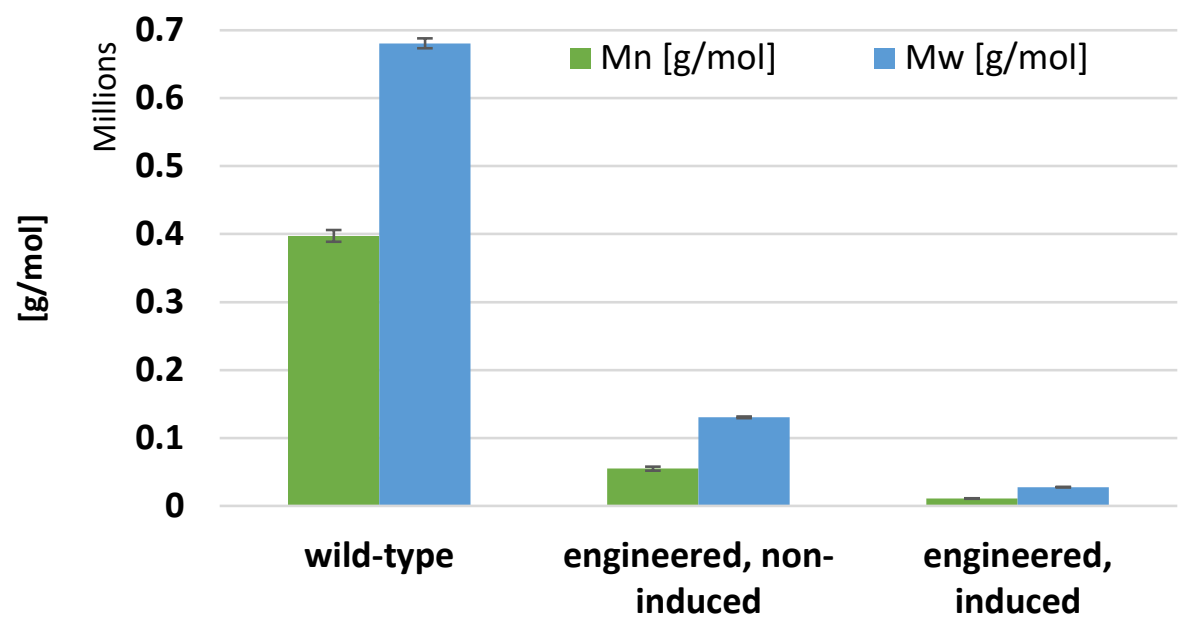

Figure 2: Molecular weight distribution $\left(\mathrm{M}_{\mathrm{n}}\right.$ and $\left.\mathrm{M}_{\mathrm{w}}\right)$ for PHA obtained from wild-type C. necator H16, and engineered C. necator H16 ( $\triangle$ phaC1 pCM66T_PBAD-hadA-phaC1437, non-induced and fully induced, respectively). 
To determine the cause of this correlation, expression-levels of the PHA synthase (and CoA transferase) during induced and non-induced conditions were compared qualitatively. In the latter case the proteins were not detected (cf. supplementary material 1, figures S1 \& S2), albeit catalytic activity of the PHA synthase apparently existed. The hypothesis is that the PHA synthase is highly active so that even very low (leaky) expression (that is virtually non-detectable) allows for formation of PHA. This would also explain the reduction in molecular weight of the polymer when expression is fully induced, as the high activity in combination with high abundance of the catalyst could lead to (local) depletion of substrate and subsequently premature termination of chain-elongation. A congruent phenomenon has been described when shuffling gene order of the natural phaCAB operon (31).

The molecular weight of other non-natural (aromatic) PHAs was in the same order of magnitude as for the PHB from the transgenic strains, as was the inverse correlation between enzyme expression and polymer molecular weight. The PDI of non-natural polyesters was generally higher than that of natural PHB (natural $<2<$ non-natural), where PDIs where highest in cases where enzyme expression was induced. Hence, it appears that tight, individual, and carefully balanced control of the expression-levels of the enzymes is compulsory in order to fine-tune polymer quality. Extended data containing the $M_{w}, M_{n}$ and PDI of the different PHAs can be found in the supplementary material 1. 


\section{Autotrophic production of Aromatic Polyesters in Bio-electrochemical System}

C. necator derives the electrons required for reduction and subsequent assimilation of carbon dioxide from molecular hydrogen. Aerobic gas-fermentation, however, is costly and involves serious safety concerns. Therefore, innovative solutions have been proposed that allow in-situ formation of $\mathrm{H}_{2}$ via electrochemical water splitting in a bio-electrochemical system (BES) (32-34). To demonstrate the sustainable production of novel aromatic polyesters via microbial electrosynthesis (MES), engineered C. necator H16 $\Delta$ phaC1 pCM66T_P $\mathrm{PAD}_{\mathrm{BA}}$-hadA-phaC1437 (hadA-strain) was cultivated in a single-chamber BES with $\mathrm{CO}_{2}$ and electrical current (to generate oxyhydrogen in-situ) as only inputs (Figure 4, see also supplementary material 1 , Figure S5). In the membrane-less system, a constant current was applied, which led to water being split into oxygen at the anode and hydrogen at the cathode. $\mathrm{CO}_{2}$ was continuously purged into the reactor, providing a gas-mix for chemolithotrophic growth of $C$. necator. The BES was inoculated from a culture grown on a gaseous $\mathrm{H}_{2} / \mathrm{CO}_{2} / \mathrm{O}_{2}$ mixture to facilitate adaptation to electroautotrophic conditions, which resulted in immediate growth in the BES (cf. Figure 4) with no lagphase. Preliminary experiments (data not shown) suggested that the amount of nitrogen-source to achieve limiting-conditions and initiate PHA accumulation was critical in the BES. Consequently, the concentration of ammonium salt in the medium was reduced and monitored throughout the experiment. Polymer precursor (PheLA) was added in two steps to minimize toxic effects. Under conditions of MES, growth rate was lower as compared to growth on gas (BES: $t_{D} \approx 26 \mathrm{~h}$ vs. serum-bottles: $t_{D} \approx 10 \mathrm{~h}$, data not shown), which can be explained with mass-transfer limitations in the BES (ambient pressure and limited agitation). Nevertheless, significant biomass was accumulated, exceeding batch-experiments in serumbottles: a maximum $\mathrm{OD}_{600}$ of 6.2 , corresponding to a biomass concentration of $\approx 1.8 \mathrm{~g} / \mathrm{L}$, was reached after $90 \mathrm{~h}$. The culture was harvested after $140 \mathrm{~h}$ and extraction of polyesters yielded an aromatic polyester, which was identified as $\mathrm{P}$ (3HB-co-PheLA) by means of ${ }^{1} \mathrm{H}-\mathrm{NMR}$ spectroscopy. The content of non-natural monomer was lower than on fructose (48:2 under autotrophic vs. 2:1 under heterotrophic conditions, for $3 \mathrm{HB}$ to PheLA), which could be explained with lower concentration of precursor ( $1 / 4^{\text {th }}$ i.e., $5 \mathrm{mM}$ PheLA) and inducer $\left(1 / 10^{\text {th }}\right.$ i.e., $0.1 \mathrm{~g} / \mathrm{L}$ arabinose) in the microbial medium, as well as limited energy available to metabolism under autotrophic conditions (21). Nevertheless, this demonstrates feasibility to produce these novel polymers from C1-feedstocks and electrical energy, which could electrify the materials industry and, when powered by renewable sources, would further close the loop to integrate this sector into a circular economy (2). 


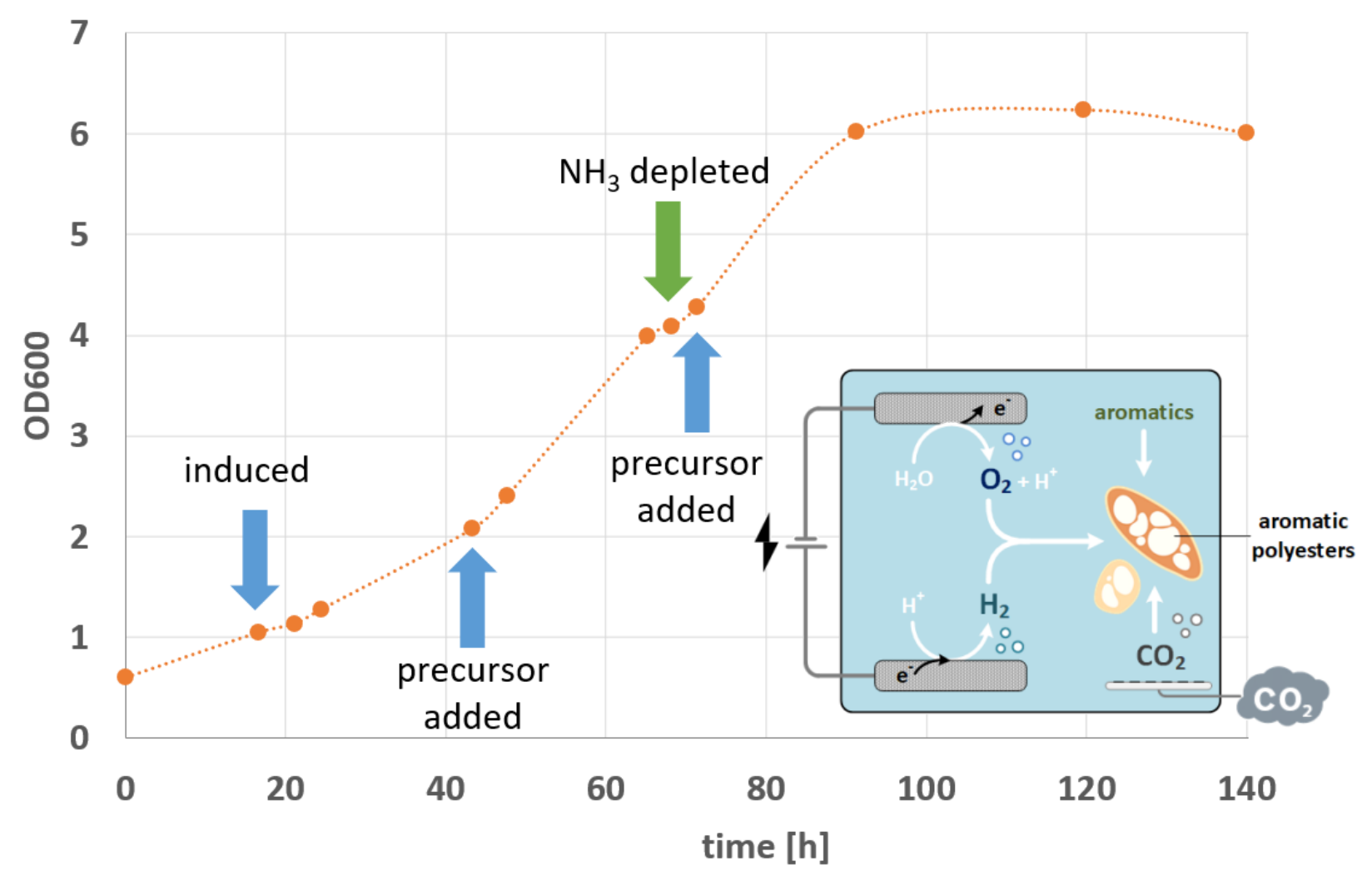

Figure 4: Cultivation-profile (growth by means of OD) of representative experiment with transgenic $C$. necator $\mathrm{H} 16$ $\triangle p h a C 1$ pCM66T_PBA-hadA-phaC1437 in bio-electrochemical system (BES). Induction of expression, addition of aromatic polymer-precursor and depletion of nitrogen source as indicated. The insert on the bottom right shows a schematic of the BES, which evolves $\mathrm{H}_{2}$ at the cathode and $\mathrm{O}_{2}$ at the anode as electron carrier and acceptor for autotrophic growth and production of aromatic polyesters from $\mathrm{CO}_{2}$ and electricity.

\section{Assessing Biosynthesis of Novel Bio-Polyesters through Metabolic Modelling}

In support of the efforts described above, an in silico analysis was conducted to assess feasibility of de novo production of the obtained co-polymers solely from basic carbon-sources. For simplification, only homo-polymers where considered. A reconstructed metabolic model of $C$. necator was amended with biochemical pathways for formation of several aliphatic or aromatic hydroxy acids and polymerization thereof, which in some cases were hypothetical (cf. supplementary material 1, figure S6 and supplementary material 3). Using elementary flux-mode analysis (EMA), the production capacity for the different (non-natural) polyesters was compared on fructose, glycerol, acetate, formate and carbon dioxide + hydrogen, in terms of maximum theoretical product yield. The results are shown in Figure 5, the corresponding numerical carbon-yields can be found in supplementary material 3. 


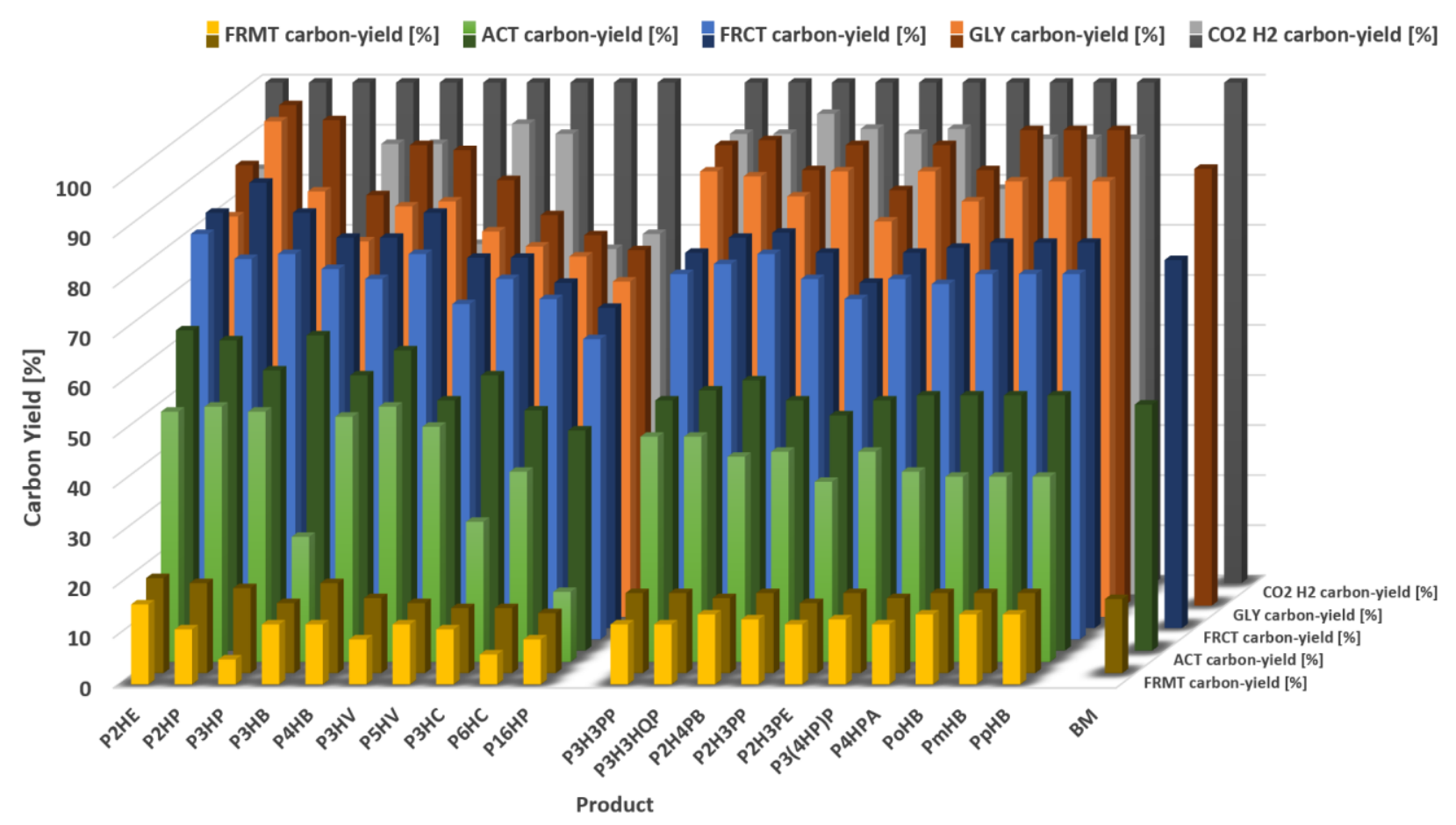

Figure 5: Theoretical maximum carbon-yields for a range of aliphatic as well as aromatic PHAs, producible from different carbon-/ energy-sources with engineered C. necator. Lighter shaded bars are product carbon-yields that allow for simultaneous growth, while darker shaded bars are absolute maximum theoretical product carbonyields. The far-right columns represent the absolute maximum biomass yields, obtainable on the different carbonsources. Substrates: $\mathrm{FRMT}=$ formate, $\mathrm{ACT}=$ acetate, $\mathrm{FRC}=$ fructose, $\mathrm{GLY}=$ glycerol; $\mathrm{CO2} \mathrm{H2}$, carbon dioxide + hydrogen. Products: $\mathbf{P 2 H E}=$ poly(2-hydroxyethanoate), $\mathbf{P 2 H P}=$ poly(2-hydroxypropanoate) [poly(lactate)], $\mathrm{P} 3 \mathrm{HP}$ = poly(3-hydroxypropanoate), $\mathrm{P} 3 \mathrm{HB}=$ poly(3-hydroxybutyrate), $\mathrm{P} 4 \mathrm{HB}=$ poly(4-hydroxybutyrate), $\mathrm{P} 3 \mathrm{HV}=$ poly(3hydroxyvalerate), $\mathrm{P} 5 \mathrm{HV}=$ poly(5-hydroxyvalerate), $\mathrm{P} 3 \mathrm{HC}=$ poly(3-hydroxycaproate), $\mathrm{P} 6 \mathrm{HC}=$ poly(6hydroxycaproate), $\mathrm{P} 16 \mathrm{HP}=$ poly(16-hydroxypalmitate), $\mathrm{P} 3 \mathrm{H} 2 \mathrm{PP}=$ poly(3-hydroxy-3-phenylpropanoate), P3H2HQP = poly(3-hydroxy-3-hydroquinoyl-propanoate), P2H4PB = poly(2-hydroxy-4-phenylbutanoate), P2H3PP $=$ poly(2-hydroxy-3-phenylpropanoate) [poly(phenyllactate)], $\mathrm{P} 2 \mathrm{H} 3 \mathrm{PE}=$ poly(2-hydroxy-3-phenylethanoate) [poly(mandelate)], P3(4HP)P = poly(3-(4-hydroxyphenyl)propanoate) [poly(phloretate)], $\mathrm{P} 4 \mathrm{HPA}=4$ hydroxyphenylacetate, $\mathrm{PoHB}=$ poly(orth-hydroxybenzoate), $\mathrm{PmHB}=$ poly(meta-hydroxybenzoate), $\mathrm{PpHB}=$ poly(para-hydroxybenzoate), BM = biomass. 
Bio-production of all considered aliphatic as well as aromatic PHAs for whom biochemical reactions exist that allow a metabolic pathway to be established appeared feasible from all assessed carbon-sources. This means that the targeted non-natural bio-polyesters can theoretically be produced de novo, without the need for co-feeding of polymer precursors, given that $(A)$ metabolic engineering efforts to produce the monomers are successful and $(B)$ these are polymerizable, which will likely require further protein engineering of PHA synthases to expand the enzymes functionality.

Certain feedstocks appeared superior over others in terms of theoretical maximum yield: carbon-yields on formate were lowest, followed by acetate. Fructose and glycerol, as more reduced carbon-sources, could deliver higher yields, only surpassed by $\mathrm{CO}_{2}+\mathrm{H}_{2}{ }^{1}$ The near- $100 \%$ carbon-efficiency on carboxyhydrogen can be explained with the separation of carbon- and energy-source into two chemical species, allowing certain steady-state flux distributions where as much energy as needed was directed to recycling of $\mathrm{CO}_{2}$, by means of the $\mathrm{H}_{2}$ to $\mathrm{CO}_{2}$ intake-ratio. This translates into an imperative for process control to optimize the gas-mix and/or implement effective recycling of unused substrate. The marginal yields on formate are owed to the low energy that is chemically bound by the combined carbon- and energy-carrier. Much of it is simply converted to carbon dioxide to obtain reducing equivalents to drive metabolism and little of it can be assimilated, which equals a scenario of carboxy-hydrogen feed with fixed ratio. Nevertheless, as formate can be produced electrochemically from carbon dioxide (35), recycling the inorganic carbon in a closed loop system could effectively create an analogous "open ratio" scenario where overall carbon-yields should approach those on carboxy-hydrogen (if a technical solution that is economical can be developed).

\footnotetext{
${ }^{1}$ When interpreting these results, it should be kept in mind that the model does not predict the phenotype that can be expected but is reflective of the leeway of the microbial system (i.e., cellular metabolism). In reality, many other factors can influence the actual idle state of the system, including kinetics (cf. rate-yield trade-off), which are not respected in this particular type of metabolic model.
} 


\section{Conclusion}

We designed the first microbial cell factory capable of synthesizing a biological polymer with an aromatic ring in its backbone. In this comprehensive study, production of a wide range of non-natural polyhydroxyalkanoates from sustainable feedstocks was studied in vivo and in silico. It appeared that enzyme expression-level and polymer chain-length were inversely correlated, which has wide-ranging implications for strain engineering - in particular, balancing of the catalytic rates in respect to the PHA synthase is thought to be crucial to fine-tune polymer quality.

In feeding experiments with engineered $C$. necator various non-natural copolymers of 3-hydroxybutyrate with hydroxy carbonic acids (aliphatic and aromatic) were formed. Aromatic 2-hydroxy carbonates with a phenyl-group on a side chain of two, one and without residual carbons could be incorporated in the polymer. In addition, a co-polymer containing the phenyl-group in the backbone of the polymer was formed, which could be described as a polyhydroxyarylate. This novelty paves the way towards biological production of high-strength liquid-crystal polymers. All precursors are bio-available from waste carbonsources (e.g., lignin in case of phloretic acid $(36,37)$ ) and/or can be biosynthesized de novo from onecarbon sources such as carbon dioxide. Deploying a bio-electrochemical system for cultivation of the transgenic microbial cell factory, only providing $\mathrm{CO}_{2}$ and electricity for growth, showed that aromatic polyester can also be formed under autotrophic conditions. This opens the opportunity for truly sustainable biological production of renewable plastics.

Using metabolic pathway modelling, the potential for production of a wide range of bio-polyesters was analyzed in models of $C$. necator and found to be feasible. This highlights the potential for bio-production of the non-natural polyesters formed in this study as well as others, outgoing from sustainable carbonsources, paving the way for creation of bioplastics with a wide range of properties. Extensive metabolic engineering will be required to realize the full de novo production of these polymers, however, recent development in synthetic biology and genetic tools, in particular for engineering of $C$. necator, indicate that this $\mathrm{CO}_{2}$ valorization strategy is feasible and within reach $(4,21)$. The ability of the PHA synthase to polymerize various aromatic hydroxy acids and importantly para-hydroxyphenyl-compounds is auspicious, however, much advancement is still needed to reach polymers with a significant content of aromatic in the backbone and high molecular weight.

Overall, the here demonstrated production of novel biologically accessible aromatic polyesters presents an important step in the efforts to leverage the power of biomanufacturing for the carbon-neutral (and potentially even carbon-negative) production of bio-replacement materials in order to create a sustainable chemical industry and thereby circular economy. 


\section{Materials and Methods}

\section{Strains and Media}

Rich Broth (RB) was composed of Nutrient Broth (16 g/L), Yeast Extract (10 g/L) and ammonium sulfate (5 g/L). When applicable, kanamycin (kan, $300 \mathrm{mg} / \mathrm{L}$ for C. necator and $100 \mathrm{mg} / \mathrm{L}$ for E. coli) and/or diaminopimelate (DAP, $300 \mu \mathrm{M} / 100 \mathrm{mg} / \mathrm{L}$ ) were added.

Modified Mineral Salts Medium (MSM) was based on literature (38) and contained $6.4 \mathrm{~g} / \mathrm{L} \mathrm{Na}_{2} \mathrm{HPO}_{4}$, $4.8 \mathrm{~g} / \mathrm{L} \mathrm{KH}_{2} \mathrm{PO}_{4}, 2 \mathrm{~g} / \mathrm{L} \mathrm{NH}_{4} \mathrm{Cl}, \mathrm{MgSO}_{4} 0.36 \mathrm{~g} / \mathrm{L}, \mathrm{CaCl}_{2} \times 2 \mathrm{H}_{2} \mathrm{O} 0.088 \mathrm{~g} / \mathrm{L}, 20 \mathrm{~g} / \mathrm{L}$ fructose and $1 \mathrm{~mL} / \mathrm{L}$ of $1000 \times$ trace elements $\left(0.2 \mathrm{~g} / \mathrm{L} \mathrm{CoCl}_{2} \times 6 \mathrm{H}_{2} \mathrm{O}, 0.01 \mathrm{~g} / \mathrm{L} \mathrm{CuSO}_{4} \times 5 \mathrm{H}_{2} \mathrm{O}, 0.15 \mathrm{~g} / \mathrm{L} \mathrm{FeSO}{ }_{4} \times 7 \mathrm{H} 2 \mathrm{O}, 0.06 \mathrm{~g} / \mathrm{L} \mathrm{NH} 4 \mathrm{Fe}\right.$ (III) citrate, $0.3 \mathrm{~g} / \mathrm{L} \mathrm{H}_{3} \mathrm{BO}_{4}, 0.035 \mathrm{~g} / \mathrm{L} \mathrm{MnCl}_{2} \times 4 \mathrm{H}_{2} \mathrm{O}, 0.035 \mathrm{~g} / \mathrm{L}\left(\mathrm{NH}_{4}\right) 6 \mathrm{Mo}_{7} \mathrm{O}_{24} \times 4 \mathrm{H}_{2} \mathrm{O}, 0.031 \mathrm{~g} / \mathrm{L} \mathrm{NiSO} \mathrm{N}_{4} \times 7 \mathrm{H}_{2} \mathrm{O}$, $\left.0.1 \mathrm{~g} / \mathrm{L} \mathrm{ZnSO}_{4} \times 7 \mathrm{H}_{2} \mathrm{O}\right)$. The medium was supplemented with kanamycin $(300 \mathrm{mg} / \mathrm{L})$ when applicable to ensure plasmid maintenance.

For (electro)autotrophic cultivations modified minimal medium that contained no chlorine salts to avoid electrocatalytic $\mathrm{Cl}_{2}$ formation, was adapted from literature (39). Specifically, the electro-medium contained $4.52 \mathrm{~g} / \mathrm{L} \mathrm{Na}_{2} \mathrm{HPO}_{4}, 5.17 \mathrm{~g} / \mathrm{L} \mathrm{NaH}_{2} \mathrm{PO}_{4} \times 2 \mathrm{H}_{2} \mathrm{O}, 0.17 \mathrm{~g} / \mathrm{L} \mathrm{K} \mathrm{SO}_{4}, 0.097 \mathrm{~g} / \mathrm{L} \mathrm{CaSO}{ }_{4} \times 2 \mathrm{H}_{2} \mathrm{O}, 0.8 \mathrm{~g} / \mathrm{L}$ $\mathrm{MgSO}_{4} \times 7 \mathrm{H}_{2} \mathrm{O}, 0.94 \mathrm{~g} / \mathrm{L}\left(\mathrm{NH}_{4}\right)_{2} \mathrm{SO}_{4}$ and $350 \mu \mathrm{L} / \mathrm{L}$ of $2857 \times$ of trace elements $\left(10 \mathrm{~g} / \mathrm{L} \mathrm{FeSO}{ }_{4} \times 7 \mathrm{H}_{2} \mathrm{O}, 2.4 \mathrm{~g} / \mathrm{L}\right.$ $\mathrm{MnSO}_{4} \times \mathrm{H}_{2} \mathrm{O}, 2.4 \mathrm{~g} / \mathrm{L} \mathrm{ZnSO}_{4} \times 7 \mathrm{H}_{2} \mathrm{O}, 0.48 \mathrm{~g} / \mathrm{L} \mathrm{CuSO}_{4} \times 5 \mathrm{H}_{2} \mathrm{O}, 1.8 \mathrm{~g} / \mathrm{L} \mathrm{Na}_{2} \mathrm{MoO}_{4} \times 2 \mathrm{H}_{2} \mathrm{O}, 1.5 \mathrm{~g} / \mathrm{L} \mathrm{NiSO}_{4} \times 6 \mathrm{H}_{2} \mathrm{O}$, $0.04 \mathrm{~g} / \mathrm{L} \mathrm{Co}\left(\mathrm{NO}_{3}\right)_{2} \times \mathrm{H}_{2} \mathrm{O}$ in $\left.0.1 \mathrm{M} \mathrm{HCl}\right)$. The medium was supplemented with kanamycin $(100 \mathrm{mg} / \mathrm{L})$ to ensure plasmid maintenance. For production of PHA in the bio-electrochemical system (BES), the initial concentration of $\left(\mathrm{NH}_{4}\right)_{2} \mathrm{SO}_{4}$ was further reduced to $5 \mathrm{mM}$ to achieve nitrogen-limiting conditions.

E. coli WM3064, a B2155 derivative, an auxotrophic RP4 mobilizing $\lambda$ pir cell-line (thrB1004 pro thi rpsL hsdS lacZ $\triangle$ M15 RP4-1360 $\Delta$ (araBAD)567 $\triangle$ dapA1341::[erm pir]), was a gift from the Spormann Laboratory (Stanford University). WM3064 was routinely cultivated on LB (solid or liquid, at $30^{\circ} \mathrm{C}$ ) supplemented with DAP $(300 \mu \mathrm{M})$ and kanamycin $(50 \mu \mathrm{g} / \mathrm{mL})$ as applicable. C. necator $\mathrm{H} 16$ and C. necator $\mathrm{H} 16 \Delta$ phaC1 were gifts from the Silver Laboratory (Harvard Medical School) (22) and routinely grown at $30^{\circ} \mathrm{C}$ on solid or liquid RB or MSM. A comprehensive list of the strains used and constructed in this study can be found in table 2 .

Table 2: strains used in this study.

\begin{tabular}{|c|c|c|}
\hline Strain & Genotype & Source \\
\hline E. coli WM3064 & & (40) \\
\hline E. coli WM3064 pCM66T_PBAD-RFP & & this study \\
\hline E. coli WM3064 pCM66T_PBAD-pct540-phaC1437 & & this study \\
\hline E. coli WM3064 pCM66T_PBAD-hadA-phaC1437 & & this study \\
\hline \multicolumn{3}{|l|}{ C. necator $\mathrm{H} 16$} \\
\hline C. necator $\mathrm{H} 16 \Delta$ phaC1 & $\mathrm{H} 16 \Delta p h a C 1$ & $(22)$ \\
\hline C. necator H16 $\Delta$ phaC1 pCM66T_P $\mathrm{PAD}_{\mathrm{BA}-\mathrm{RFP}}$ & H16 $\Delta p h a C 1$ RFP & this study \\
\hline C. necator H16 $\Delta$ phaC1 pCM66T_P $\mathrm{P}_{\mathrm{BAD}}-p c t 540$-phaC1437 & H16 $\Delta$ phaC1 pct540 phaC1437 & this study \\
\hline C. necator H16 $\Delta$ phaC1 pCM66T_P ${ }_{\text {BAD-hadA-phaC1437 }}$ & H16 $\Delta$ phaC1 hadA phaC1437 & this study \\
\hline
\end{tabular}




\section{Genetic Engineering}

\section{Vector Construction}

The RK2/RP4 oriV (IncP) plasmid pCM66T was obtained from AddGene. pBBR1MCS_PBAD-RFP, a derivate of pBBR1MCS with a red fluorescent protein (RFP) under control of the araBAD promoter, was a gift from the Silver Laboratory (Harvard Medical School). pCM66T_P $\mathrm{P}_{\mathrm{BAD}}$-RFP was constructed by cloning the $\mathrm{P}_{\mathrm{BAD}^{-}}$ RFP cassette into pCM66T using NEBuilder, replacing the polylinker and its regulatory elements. The protein sequences of Q9L3F7_CLOPR (pct), Q188I3_PEPD6 (hadA) and B9W0T0_9PSED (phaC) were derived from UniProt, implementing the previously described mutations (V193A for pct540 and E130D, S325T, S477G, Q481K for phaC1437) as applicable. The sequences were fused with a C-terminal tripleglycine-spacer and tetracysteine- (Lumio)-tag and codon-optimized for expression in C. necator with GeneArt $^{\circledR}$ (Invitrogen). The genes were arranged in a single operon under control of the araBAD promoter in combination with the strong T7 ribosomal binding-site and a T7Te - rrnB T1 double-terminator. The plasmids pCM66T_P $\mathrm{PAD}_{\mathrm{BD}}$-pct540-phaC1437 and pCM66T_P $\mathrm{P}_{\mathrm{BAD}}$-hadA-phaC1437 were constructed by GenScript, cloning the synthetic operons containing pct540 \& phaC1437 and hadA \& phaC1437, respectively, into pCM66T_ $\mathrm{P}_{\mathrm{BAD}}-\mathrm{RFP}$ (cf. supplementary material 2).

\section{Conjugation}

Plasmid vectors were introduced into C. necator by conjugation, using the E. coli donor-strain WM3064, which had been transformed with the plasmid vectors pCM66T_P $\mathrm{BAD}_{\text {- }}$ pct540-phaC1437 and pCM66T_P BAD- $^{-}$ hadA-phaC1437 using the Mix \& Go! E. coli Transformation Kit (Zymo).

Conjugation was performed as follows: The recipient strain ( $\mathrm{H} 16 \Delta p h a \mathrm{C} 1$ ) was incubated at $30^{\circ} \mathrm{C}$ on $\mathrm{RB}$ plates for two days, simultaneously the donor strains carrying the plasmid vectors were incubate at $37^{\circ} \mathrm{C}$ on LB + Kan + DAP plates for one day. On the third day the donor strains were inoculate in liquid LB + Kan + DAP and incubated overnight with shaking at $37^{\circ} \mathrm{C}$, the recipient strain was inoculated in $\mathrm{RB}$ and incubate overnight with shaking at $30^{\circ} \mathrm{C}$. On the fourth day $3 \mathrm{~mL}$ of LB + DAP (but no antibiotics) were inoculated with $6 \mu \mathrm{L}$ of each overnight donor-strain culture and incubated with shaking at $37^{\circ} \mathrm{C}$. At the same time $20 \mu \mathrm{L}$ of overnight $C$. necator culture was added in $10 \mathrm{~mL} \mathrm{RB}$ and incubated at $30^{\circ} \mathrm{C}$ while shaking. After $4 \mathrm{~h} 3 \mathrm{~mL}$ of the $E$. coli and $10 \mathrm{~mL}$ of the $C$. necator culture were combined and spun down ( $4816 \mathrm{~g}$ for $10 \mathrm{~min}$ ). The supernatant was discarded, and the cells were re-suspended in $200 \mu \mathrm{L} \mathrm{RB}+$ DAP. A "blob" of the cell mixture was pipetted on an RB + DAP plate and incubated at $30^{\circ} \mathrm{C}$ overnight (face of plate up). On day five all of the grown biomass was collected from the overnight plate with an inoculation loop and suspended into $500 \mu \mathrm{L}$ of $25 \%$ glycerol and diluted $1: 10$ and 1:100. All three concentrations were plated on separate $\mathrm{RB}+$ kan plates. The plates were incubated at $30^{\circ} \mathrm{C}$, colonies that appeared after $2-3$ days were picked and isolated on separate $\mathrm{RB}+$ kan plates for screening. 


\section{Cultivation of Microbes}

\section{Cultivation of $C$. necator in Shake- and Serum-Flasks}

Liquid cultures under heterotrophic conditions were conducted in $500 \mathrm{~mL}$ vented, baffled shake-flasks (WHEATON ${ }^{\circledR}$ Erlenmeyer Flasks with DuoCap ${ }^{\circledR}$, DWK Life Sciences), incubated with shaking at $180 \mathrm{rpm}$ on an innova 2300 platform shaker (New Brunswick Scientific) at $30^{\circ} \mathrm{C}$. For feeding experiments, precultures of the engineered $C$. necator strains were inoculated in liquid $\mathrm{RB}+$ kan $(50 \mathrm{~mL})$ from solid $\mathrm{RB}+$ kan and grown over-night. In the morning the medium was exchanged for MSM + kan, diluting the culture 1:2 (in $100 \mathrm{~mL}$ ). In the afternoon the seed-culture was washed with MSM and again diluted 1:2 (in $200 \mathrm{~mL}$ ) with $\mathrm{MSM}+$ kan + polymer-precursor and induced with arabinose $(1 \mathrm{~g} / \mathrm{L}$, unless indicated otherwise) in the evening. OD was monitored accompanied by collection of supernatant samples. The cultures were harvest after approx. $48 \mathrm{~h}$ or when no more increase in biomass was observed for $12 \mathrm{~h}$.

Precultures for the bio-electrochemical system were done in two steps: $125 \mathrm{~mL}$ serum bottles $(25 \mathrm{~mL}$ liquid medium, $100 \mathrm{~mL}$ gas headspace) were filled with $25 \mathrm{~mL}$ electro-medium and sealing with butyl rubber stopper and crimp-cap. Starting with fructose $(1 \mathrm{~g} / \mathrm{L})$ as carbon-source, the medium was inoculated with C. necator H16 $\Delta$ phaC1 pCM66T_P $\mathrm{PAD}_{\mathrm{BD}}$-hadA-phaC1437 from solid RB + kan (heterotrophic growth) and incubated at $30^{\circ} \mathrm{C}$ with shaking at $200 \mathrm{rpm}$ overnight. Subsequently, these cultures were transferred to autotrophic conditions on $\mathrm{H}_{2} / \mathrm{CO}_{2} / \mathrm{O}_{2}$ : the initial gas-phase was $\mathrm{H}_{2} / \mathrm{CO}_{2}(80 \% / 20 \%)$ at $17 \mathrm{psi}$, which was further pressurized to $22 \mathrm{psi}$ with $\mathrm{O}_{2}(100 \%)$, resulting in a final gas composition of 64:16:20 $\left(\mathrm{H}_{2} / \mathrm{CO}_{2} / \mathrm{O}_{2}\right)$. After three days of incubation autotrophic growth was observed, reaching a maximum cell density of OD $3.8 \pm 0.15$ within $48 \mathrm{~h}$ (data not shown). For transfer to the BES exponentially growing cultures were harvested at an $O D$ of $\approx 0.7$ (by centrifugation at $4000 \times$ g for $6 \mathrm{~min}$ ) and re-suspended in $25 \mathrm{~mL}$ fresh medium.

\section{Cultivation of $C$. necator in Bio-electrochemical System}

The bio-electrochemical system was a custom $(500 \mathrm{~mL}$ ) glass vessel with rubber-stopper side ports (Adams \& Chittenden Scientific). The reactor was operated membrane-less as three-electrode set up, magnetically stirred at $300 \mathrm{rpm}$. The cathode was a Nickel-Molybdenum alloy on graphite support (total surface area $50 \mathrm{~cm}^{2}$ ), which has been characterized previously and found to evolve $\mathrm{H}_{2}$ at $100 \%$ selectivity under biologically relevant conditions $(41,42)$. The anode was platinized titanium mesh (PLANODE1X4, TWL) and an $\mathrm{Ag} / \mathrm{AgCl}$ reference electrode $\left(\mathrm{NaCl}\right.$ saturated; $\left.\mathrm{RE}-5 \mathrm{~B}, \mathrm{BASi}{ }^{\circledR}\right)$, both of which were inserted via a rubber stopper side port. The electrochemical reactor was controlled by applying a constant current of 100 mA using a multichannel potentiostat (VMP3; BioLogic Science Instruments, EC-Lab 11.21). This way, a constant amount of electron flow and therefore constant flow of $\mathrm{H}_{2}$ and $\mathrm{O}_{2}$ was provided. In abiotic pretests (data not shown) the reactor headspace was analyzed (via GC) to confirm that $\mathrm{H}_{2}$ and $\mathrm{O}_{2}$ were the sole gaseous products. The reactor was filled with $300 \mathrm{~mL}$ medium, and $\mathrm{CO}_{2}$ was supplied via a mass flow controller (EL-Flow F-100D, Bronkhorst ${ }^{\circledR}$ ) at a constant flow rate of $1 \mathrm{~mL} / \mathrm{min}$. Before inoculation, the BES was operated for at least one hour under abiotic conditions to saturate the medium with the gases. The reactor was inoculated with $25 \mathrm{~mL}$ of concentrated cell-suspension from exponentially growing, autotrophic cultures, so that a starting OD between 0.5-0.6 (and final liquid volume of $325 \mathrm{~mL}$ ) was 
achieved. Preliminary tests showed that under autotrophic growth conditions accumulation of PHA required tight limitation of the nitrogen-source. Therefore, the initial concentration of ammonium salt in the BES was reduced to $5 \mathrm{mM}$ and consumption was monitored ("EasyStrips" Ammonia Test Strips, Tetra ${ }^{\circledR}$ $\mathrm{GmbH}$, sensitivity $<0.5 \mathrm{mg} / \mathrm{L}$ ) throughout the experiment. Growth and $\mathrm{pH}$ were also measured by drawing samples manually. After $24 \mathrm{~h}$ the culture was induced with arabinose $(0.1 \mathrm{~g} / \mathrm{L}$ final conc.). $24 \mathrm{~h}$ after induction, the first dose of precursor was added ( $2.5 \mathrm{mM}$ final conc.), and the second dose (additional $2.5 \mathrm{mM}$, i.e. $5 \mathrm{mM}$ total) when the nitrogen-source was depleted. The experiment was terminated when the $O D$ became stationery, cells were harvested via centrifugation followed by polymer extraction. Pictures of the set up can be found in supplementary material 1 (Figure S5).

\section{Extraction of PHAs}

Liquid culture of $C$. necator was harvested by centrifugation and the cell pellet was freeze dried. After determining the dry cell weight (CDW), PHAs were extracted by lysis of the cell pellet (wet or dry) with $10 \%$ sodium hypochlorite solution (Honeywell Fluka ${ }^{\mathrm{TM}}$ ) using approx. $0.2 \mathrm{~L} / \mathrm{g}_{\mathrm{CDW}}$. The pellet was completely suspended and incubated at room-temperature for $20 \mathrm{~min}$ with intermittent mixing. The suspension was diluted with water 1:2 and centrifuged at $4816 \times \mathrm{g}$ for $20 \mathrm{~min}$. The remaining solids, containing the PHAs, were washed twice with water and once with methanol, repeating the centrifugation step. The dried PHA was weight to determine product yield, dissolved in chloroform, filtered with a $0.2 \mu \mathrm{m}$ PTFE "Titan3" (Thermo Scientific ${ }^{\mathrm{TM}}$ ) syringe filter and dried for analysis.

\section{Protein Extraction and Detection}

Culture derived from distinct time-points of a batch cultivation (exponential-phase / stationary-phase) was collected (sample volume $[\mathrm{mL}] \approx 10 / \mathrm{OD}_{600}$ ) and cells were pellet by centrifugation $\left(4816 \times \mathrm{g}\right.$ at $4{ }^{\circ} \mathrm{C}$ for $10 \mathrm{~min}$ ). The pellet was washed with purified water and stored as cell-paste at $-20^{\circ} \mathrm{C}$ for later processing. For extraction of proteins, CelLytic ${ }^{\mathrm{TM}} \mathrm{B}$ (Sigma) was used as per manufacturer's directions (approx. $1 \mathrm{~mL}$ per cells from $10 \mathrm{~mL}$ culture at an OD of 1), in combination with Protease Inhibitor Cocktail (SigmaAldrich). The mixture was vortexed for $2 \mathrm{~min}$ to lyse cells and extract the soluble protein. Centrifugation (4816×g for $10 \mathrm{~min}$ ) pelleted the cell debris; the supernatant, which contained the soluble proteins, was separated. Total protein concentration was determined using the BCA Protein Assay Kit (Pierce ${ }^{\mathrm{TM}}$ ). Using the Lumio $^{\mathrm{TM}}$ Green Detection Kit (ThermoFisher) as per manufacturer's directions $10 \mu \mathrm{g}$ crude protein extract of each sample were prepared for gel electrophoresis. Size-separation was performed on a Bolt ${ }^{\mathrm{TM}}$ 4-12\% Bis-Tris Plus Gel (ThermoFisher), run at $150 \mathrm{~V}$ for approx. 40 min with Bolt ${ }^{\mathrm{TM}}$ MES SDS Running Buffer (ThermoFisher). The marker was BenchMark ${ }^{\mathrm{TM}}$ Fluorescent Protein Standard (ThermoFisher). A GelDoc (BioRad) was used to visualize fluorescent-conjugated proteins. For visualization of all proteins, the gels were re-stained with One-Step Lumitein ${ }^{\mathrm{TM}}$ Protein Gel Stain (Biotium) as per manufacturer's directions and imaged again as before. 


\section{Analytics}

\section{Determination of OD and cell dry weight correlation}

Microbial growth was characterized by measuring the optical density at $600 \mathrm{~nm}\left(\mathrm{OD}_{600}\right)$ with a DR2800 Portable Spectrophotometer $(\mathrm{HACH})$ for shake-flask cultures and Ultrospec ${ }^{\mathrm{TM}} 2100$ pro (Amersham BioSciences) in case of MES.

A correlation between $\mathrm{OD}_{600}$ and biomass $(\mathrm{BM}$ ) concentration was determined gravimetrically (data not shown) from batch shake-flask cultivations with the wild-type (five samples) and engineered strains (five samples of the pct540-strain, 10 samples of the hadA-strain) of $C$. necator. Shake-flask cultures of $50 \mathrm{~mL}$ with different cell densities were harvested via centrifugation and vacuum dried. The average quotient of $\mathrm{OD}_{600} / \mathrm{BM}$ (dry weight in $\mathrm{mg}$ ) from the total of 20 samples was $0.3 \pm 0.04$, such that the correlation is $\mathrm{OD}_{600} \times 0.3=\mathrm{BM}[\mathrm{g} / \mathrm{L}]$.

HPLC

Quantification of fructose in fermentation broth was based on a previously published HPLC-method for detection of organic acids (43). In short, the procedure was as follows: Samples ( $1 \mathrm{~mL}$ ) were filtered (PVDF or PES syringe filters, $0.2 \mu \mathrm{m}$ pore-size) and diluted 1:100 into HPLC sampling vials. Analysis of $50 \mu \mathrm{L}$ sample-volume was performed on an 1260 Infinity HPLC system (Agilent), using an Aminex HPX87H column (BioRad) with $5 \mathrm{mM} \mathrm{H}_{2} \mathrm{SO}_{4}$ as the eluent, at a flow rate of $0.7 \mathrm{~mL} / \mathrm{min}$. Fructose was identified and quantified by comparison to standards $(3 \mathrm{~g} / \mathrm{L}, 1.5 \mathrm{~g} / \mathrm{L}, 0.6 \mathrm{~g} / \mathrm{L}, 0.3 \mathrm{~g} / \mathrm{L}, 0.15 \mathrm{~g} / \mathrm{L}, 0.03 \mathrm{~g} / \mathrm{L}$ ), according to retention time $(8.8 \mathrm{~min})$ using a refractive index detector $\left(35^{\circ} \mathrm{C}\right)$.

\section{Nuclear Magnetic Resonance (NMR) Spectroscopy}

NMR samples were prepared as previously reported (44). In short, a few mg of polymer were dissolved in deuterated chloroform and ${ }^{1} \mathrm{H}-\mathrm{NMR}$ as well as ${ }^{13} \mathrm{C}-\mathrm{NMR}$ spectra were recorded at $25^{\circ} \mathrm{C}$ on a Unity INOVA ${ }^{\mathrm{TM}}$ 500 NMR Spectrometer (Varian Medical Systems) with chemical shifts referenced in ppm relative to tetramethylsilane.

\section{Gas Chromatography-Mass Spectrometry (GC-MS)}

GC-MS analysis was adopted from literature (22). Between 3-70 mg of extracted PHAs were transferred to crimped vials and $2 \mathrm{~mL}$ chloroform $+2 \mathrm{~mL}$ methanol with $15 \% \mathrm{HCl}$ was added. The vials were closed and incubated for $1-2 \mathrm{~h}$ at $100^{\circ} \mathrm{C}$. Vials were cooled on ice and content was combined with $4 \mathrm{~mL} \mathrm{H}_{2} \mathrm{O}$ in a screw cap glass vial. The mixture was vortexed and phases were separated by centrifugation at $3000 \mathrm{rpm}$ for $10 \mathrm{~min}$. The lower chloroform phase was transferred into a GC-MS vial for analysis. Samples were analyzed on a 7890 / 5975 inert XL GCMS (Agilent Technologies) with a J\&W CP-TAP CB column CP7483 (Agilent Technologies). Analytes were heated on a gradient from $35-250^{\circ} \mathrm{C}$ at $2^{\circ} \mathrm{C} / \mathrm{min}$. Copolymers were detected with mass spectra of hydroxy acid methyl esters at $\mathrm{m} / \mathrm{z}=1-3$ and NIST Mass Spectral Library. 


\section{Gel Permeation Chromatography (GPC)}

Polystyrene calibrated (from $M_{p}=500-275,000 \mathrm{~g} / \mathrm{mol}$ ) molecular weights were determined using a GPCmax autosampler (Viscotek) with $300 \mathrm{~mm} \times 7.7 \mathrm{~mm} \mathrm{GPC}$ column (Waters ${ }^{\mathrm{TM}}$ ) in $\mathrm{CHCl}_{3}$ at $25^{\circ} \mathrm{C}$ at a flow rate of $1 \mathrm{~mL} / \mathrm{min}$ and $\mathrm{S} 3580$ refractive index detector (Viscotek).

\section{Metabolic Modelling}

Based on previously established metabolic networks of $C$. necator for elementary flux-mode analysis (45, 46), the present model was fundamentally re-constructed, refined and fully compartmentalized. Expansions were made to describe $\mathrm{C} 1$ - and energy-metabolism more precisely $(26,47)$ and the model was amended with additional carbon assimilation and product formation pathways (cf. supplementary material 1, figure S5), deducted from metabolic databases such as KEGG (48, 49). Reaction thermodynamics of the heterologous pathways were verified with eQuilibrator (50).

Elementary flux modes were calculated in $\operatorname{MATLAB}^{\circledR}$ (MathWorks ${ }^{\circledR}$ ), using 'FluxModeCalculator' (51), and evaluated as described previously (52). Balances were established around boundary reactions, allowing carbon-yields [C-mol/C-mol] for all products to be determined.

\section{Supporting Information}

- $\quad$ Appendix: Documentation containing growth-data and protein gels, NMR \& GC-MS spectra and extended GPC data (supplementary material 1 )

- $\quad$ Datasets: Annotated vector maps of genetic constructs (supplementary material 2) \& spreadsheet containing metabolic models of $C$. necator (supplementary material 3 )

\section{Acknowledgements}

This study was supported by a Stanford Natural Gas Initiative (NGI) program grant (SPO \#139138), as well as NASA grant or cooperative agreement award number NNX17AJ31G. Any opinions, findings, and conclusions or recommendations expressed in this material are those of the author and do not necessarily reflect the views of the National Aeronautics and Space Administration (NASA).

\section{Author Contributions}

NJHA conceived the study, designed, and conducted the experiments and composed the manuscript. VEP, FK, MZ performed analytics (NMR \& GPC, HPLC, GC-MS, respectively), SNN helped with strain construction. FK designed and conducted experiments in the bio-electrochemical system. RWW and CSC supported and advised the project. All authors have read and approved the final manuscript.

\section{Competing Interests}

The authors declare no competing interests. 


\section{References}

1. J. Smith, S. Vignieri, A devil's bargain. Science 373, 34-35 (2021).

2. S. R. Nicholson, N. A. Rorrer, A. C. Carpenter, G. T. Beckham, Manufacturing energy and greenhouse gas emissions associated with plastics consumption. Joule 5, 673-686 (2021).

3. R. Geyer, J. R. Jambeck, K. L. Law, Production, use, and fate of all plastics ever made. Science Advances 3, e1700782 (2017).

4. S. Y. Lee et al., A comprehensive metabolic map for production of bio-based chemicals. Natue Catalysis 2, 18-33 (2019).

5. X. Chen, N. Yan, A brief overview of renewable plastics. Materials Today Sustainability 7-8, 100031 (2020).

6. L. D. Ellis et al., Chemical and biological catalysis for plastics recycling and upcycling. Nature Catalysis 4, 539-556 (2021).

7. G. Atiwesh, A. Mikhael, C. C. Parrish, J. Banoub, T.-A. T. Le, Environmental impact of bioplastic use: A review. Heliyon 7, e07918 (2021).

8. J. M. Clomburg, A. M. Crumbley, R. Gonzalez, Industrial biomanufacturing: The future of chemical production. Science 355, aag0804 (2017).

9. A. M. Brandon, C. S. Criddle, Can biotechnology turn the tide on plastics? Curr Opin Biotech 57, 160-166 (2019).

10. P. J. Strong et al., The Opportunity for High-Performance Biomaterials from Methane. Microorganisms 4, 11 (2016).

11. Z. Li, J. Yang, X. J. Loh, Polyhydroxyalkanoates: opening doors for a sustainable future. NPG Asia Materials 8, e265-e265 (2016).

12. B. Andreeßen, N. Taylor, A. Steinbüchel, V. Müller, Poly(3-Hydroxypropionate): a Promising Alternative to Fossil FuelBased Materials. Applied and Environmental Microbiology 80, 6574-6582 (2014).

13. C. Utsunomia, Q. Ren, M. Zinn, Poly(4-Hydroxybutyrate): Current State and Perspectives. Frontiers in Bioengineering and Biotechnology 8 (2020).

14. A. G. Aduhene et al., Poly(3-hydroxypropionate): Biosynthesis Pathways and Malonyl-CoA Biosensor Material Properties. Frontiers in Bioengineering and Biotechnology 9 (2021).

15. M. Ishii-Hyakutake, S. Mizuno, T. Tsuge, Biosynthesis and Characteristics of Aromatic Polyhydroxyalkanoates. Polymers 10, 1267 (2018).

16. T. Liu et al., Synthesis of Polymandelide: A Degradable Polylactide Derivative with Polystyrene-like Properties. Macromolecules 40, 6040-6047 (2007).

17. T. L. Simmons, G. L. Baker, Poly(phenyllactide): Synthesis, Characterization, and Hydrolytic Degradation. Biomacromolecules 2, 658-663 (2001).

18. J. E. Yang et al., One-step fermentative production of aromatic polyesters from glucose by metabolically engineered Escherichia coli strains. Nat Commun 9, 79 (2018).

19. X. Jin, C. Carfagna, L. Nicolais, R. Lanzetta, Synthesis and characterization of potentially biodegradable thermotropic polyesters based on $p$-hydroxybenzoic acid and glycolic acid. Journal of Polymer Science Part A: Polymer Chemistry 32, 3115-3122 (1994).

20. A. Reina, A. Gerken, U. Zemann, H. R. Kricheldorf, New polymer syntheses, 101. Liquid-crystalline hyperbranched and potentially biodegradable polyesters based on phloretic acid and gallic acid. Macromolecular Chemistry and Physics 200, 1784-1791 (1999).

21. J. Panich, B. Fong, S. W. Singer, Metabolic Engineering of Cupriavidus necator H16 for Sustainable Biofuels from CO2. Trends in Biotechnology 39, 412-424 (2021).

22. S. N. Nangle et al., Valorization of $\mathrm{CO} 2$ through lithoautotrophic production of sustainable chemicals in Cupriavidus necator. Metabolic Engineering 62, 207-220 (2020).

23. S. J. Park et al., Metabolic engineering of Ralstonia eutropha for the production of polyhydroxyalkanoates from sucrose. Biotechnology and Bioengineering 112, 638-643 (2015).

24. S. Mizuno, A. Hiroe, T. Fukui, H. Abe, T. Tsuge, Fractionation and thermal characteristics of biosynthesized polyhydoxyalkanoates bearing aromatic groups as side chains. Polymer Journal 49, 557-565 (2017).

25. T. H. Yang et al., Biosynthesis of polylactic acid and its copolymers using evolved propionate CoA transferase and PHA synthase. Biotechnology and Bioengineering 105, 150-160 (2010).

26. N. J. Claassens et al., Phosphoglycolate salvage in a chemolithoautotroph using the Calvin cycle. Proceedings of the National Academy of Sciences 117, 22452-22461 (2020).

27. T. Tsuge, K. Tanaka, M. Shimoda, A. Ishizaki, Optimization of I-lactic acid feeding for the production of poly-d-3hydroxybutyric acid by Alcaligenes eutrophus in fed-batch culture. Journal of Bioscience and Bioengineering 88, 404409 (1999).

28. S. L. Riedel, J. Lu, U. Stahl, C. J. Brigham, Lipid and fatty acid metabolism in Ralstonia eutropha: relevance for the biotechnological production of value-added products. Applied Microbiology and Biotechnology 98, 1469-1483 (2014).

29. T. Fukui, M. Suzuki, T. Tsuge, S. Nakamura, Microbial Synthesis of Poly((R)-3-hydroxybutyrate-co-3-hydroxypropionate) from Unrelated Carbon Sources by Engineered Cupriavidus necator. Biomacromolecules 10, 700-706 (2009). 
30. N. Lindenkamp, M. Schürmann, A. Steinbüchel, A propionate CoA-transferase of Ralstonia eutropha H16 with broad substrate specificity catalyzing the CoA thioester formation of various carboxylic acids. Applied Microbiology and Biotechnology 97, 7699-7709 (2013).

31. A. Hiroe, K. Tsuge, C. T. Nomura, M. Itaya, T. Tsuge, Rearrangement of gene order in the phaCAB operon leads to effective production of ultrahigh-molecular-weight poly[(R)-3-hydroxybutyrate] in genetically engineered Escherichia coli. Appl Environ Microbiol 78, 3177-3184 (2012).

32. K. K. Sakimoto et al., Physical Biology of the Materials-Microorganism Interface. Journal of the American Chemical Society 140, 1978-1985 (2018).

33. T. Krieg, A. Sydow, S. Faust, I. Huth, D. Holtmann, CO2 to Terpenes: Autotrophic and Electroautotrophic $\alpha$-Humulene Production with Cupriavidus necator. Angewandte Chemie International Edition 57, 1879-1882 (2018).

34. C. Liu, B. C. Colón, M. Ziesack, P. A. Silver, D. G. Nocera, Water splitting-biosynthetic system with CO2 reduction efficiencies exceeding photosynthesis. Science 352, 1210-1213 (2016).

35. M. F. Philips, G.-J. M. Gruter, M. T. M. Koper, K. J. P. Schouten, Optimizing the Electrochemical Reduction of CO2 to Formate: A State-of-the-Art Analysis. ACS Sustainable Chemistry \& Engineering 8, 15430-15444 (2020).

36. G. T. Beckham, C. W. Johnson, E. M. Karp, D. Salvachúa, D. R. Vardon, Opportunities and challenges in biological lignin valorization. Current Opinion in Biotechnology 42, 40-53 (2016).

37. A. J. Ragauskas et al., Lignin Valorization: Improving Lignin Processing in the Biorefinery. Science 344, 1246843 (2014).

38. Y.-H. Yang et al., Optimization of growth media components for polyhydroxyalkanoate (PHA) production from organic acids by Ralstonia eutropha. Applied Microbiology and Biotechnology 87, 2037-2045 (2010).

39. A. Sydow, T. Krieg, R. Ulber, D. Holtmann, Growth medium and electrolyte-How to combine the different requirements on the reaction solution in bioelectrochemical systems using Cupriavidus necator. Eng Life Sci 17, 781-791 (2017).

40. C. Dehio, M. Meyer, Maintenance of broad-host-range incompatibility group P and group Q plasmids and transposition of Tn5 in Bartonella henselae following conjugal plasmid transfer from Escherichia coli. Journal of Bacteriology 179, 538540 (1997).

41. F. Kracke et al., Robust and biocompatible catalysts for efficient hydrogen-driven microbial electrosynthesis. Communications Chemistry 2, 45 (2019).

42. F. Kracke, J. S. Deutzmann, W. Gu, A. M. Spormann, In situ electrochemical H2 production for efficient and stable powerto-gas electromethanogenesis. Green Chemistry 22, 6194-6203 (2020).

43. S. T. Lohner, J. S. Deutzmann, B. E. Logan, J. Leigh, A. M. Spormann, Hydrogenase-independent uptake and metabolism of electrons by the archaeon Methanococcus maripaludis. The ISME Journal 8, 1673-1681 (2014).

44. J. Myung et al., Long-term cultivation of a stable Methylocystis-dominated methanotrophic enrichment enabling tailored production of poly(3-hydroxybutyrate-co-3-hydroxyvalerate). Bioresource Technology 198, 811-818 (2015).

45. N. J. H. Averesch, F. Kracke, Metabolic Network Analysis of Microbial Methane Utilization for Biomass Formation and Upgrading to Bio-Fuels. Frontiers in Energy Research 6 (2018).

46. P. Unrean, K. L. Tee, T. S. Wong, Metabolic pathway analysis for in silico design of efficient autotrophic production of advanced biofuels. Bioresources and Bioprocessing 6, 49 (2019).

47. R. Cramm, Genomic View of Energy Metabolism in Ralstonia eutropha H16. Microbial Physiology 16, 38-52 (2009).

48. M. Kanehisa, S. Goto, KEGG: Kyoto Encyclopedia of Genes and Genomes. Nucleic Acids Res 28, 27-30 (2000).

49. H. Ogata et al., KEGG: Kyoto Encyclopedia of Genes and Genomes. Nucleic Acids Res 27, 29-34 (1999).

50. A. Flamholz, E. Noor, A. Bar-Even, R. Milo, eQuilibrator-the biochemical thermodynamics calculator. Nucleic Acids Res 40, D770-D775 (2011).

51. J. B. van Klinken, K. Willems van Dijk, FluxModeCalculator: an efficient tool for large-scale flux mode computation. Bioinformatics 32, 1265-1266 (2015).

52. I. Vassilev, N. J. H. Averesch, P. Ledezma, M. Kokko, Anodic electro-fermentation: Empowering anaerobic production processes via anodic respiration. Biotechnology Advances 48, 107728 (2021). 